\title{
DISABILITY, THEATRE AND POWER: \\ AN ANALYSIS OF A ONE-PERSON PLAY
}

\begin{abstract}
A thesis submitted to the Faculty of Graduate Studies and Research of Carleton University
\end{abstract}

By

Alan Mark Shain, B.A.

In Partial Fulfillment of the Requirements for the Degree of Master of Social Work

January 2006

Copyright $\odot$ Alan Mark Shain, 2006 


$\begin{array}{ll}\begin{array}{l}\text { Library and } \\ \text { Archives Canada }\end{array} & \begin{array}{l}\text { Bibliothèque et } \\ \text { Archives Canada }\end{array} \\ \begin{array}{l}\text { Published Heritage } \\ \text { Branch }\end{array} & \begin{array}{l}\text { Direction du } \\ \text { Patrimoine de l'édition }\end{array} \\ \begin{array}{l}\text { 395 Wellington Street } \\ \text { Ottawa ON K1A ON4 }\end{array} & \begin{array}{l}\text { 395, rue Wellington } \\ \text { Ottawa ON K1A ON4 } \\ \text { Canada }\end{array}\end{array}$

Your file Votre référence

ISBN: 0-494-13477-1

Ourfile Notre référence

ISBN: 0-494-13477-1

NOTICE:

The author has granted a nonexclusive license allowing Library and Archives Canada to reproduce, publish, archive, preserve, conserve, communicate to the public by telecommunication or on the Internet, loan, distribute and sell theses worldwide, for commercial or noncommercial purposes, in microform, paper, electronic and/or any other formats.

The author retains copyright ownership and moral rights in this thesis. Neither the thesis nor substantial extracts from it may be printed or otherwise reproduced without the author's permission.
AVIS:

L'auteur a accordé une licence non exclusive permettant à la Bibliothèque et Archives Canada de reproduire, publier, archiver, sauvegarder, conserver, transmettre au public par télécommunication ou par l'Internet, prêter, distribuer et vendre des thèses partout dans le monde, à des fins commerciales ou autres, sur support microforme, papier, électronique et/ou autres formats.

L'auteur conserve la propriété du droit d'auteur et des droits moraux qui protège cette thèse. $\mathrm{Ni}$ la thèse ni des extraits substantiels de celle-ci ne doivent être imprimés ou autrement reproduits sans son autorisation.
In compliance with the Canadian

Privacy Act some supporting forms may have been removed from this thesis.

While these forms may be included in the document page count, their removal does not represent any loss of content from the thesis.
Conformément à la loi canadienne sur la protection de la vie privée, quelques formulaires secondaires ont été enlevés de cette thèse.

Bien que ces formulaires aient inclus dans la pagination, il n'y aura aucun contenu manquant.

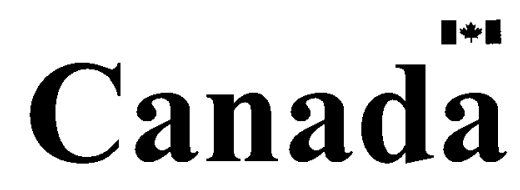




\section{ABSTRACT}

This study explores the connections that are being made between the Disability Arts and Culture Movement and the struggle for the equality and Human Rights of Disabled Peoples. A major goal of this study is to highlight arts and culture as a site of political struggle for Disabled Peoples. The analysis of a one-person play, Still Waiting for That Special Bus provides a case study of the use of theatre to challenge dominant frameworks which underlie disability oppression. The implications for social work are reflexive in nature which informs theory, research, education, training and practice when working with Disabled Peoples. 


\section{ACKNOWLEDGMENTS}

With sincere thanks and appreciation to:

Roy Hanes, thesis advisor, for your ongoing support through all phases of the project and for securing the additional financial resources which allowed me to complete the thesis, as well as to the other committee members for your interest and involvement

Gillian Walker, interim thesis advisor, for your insight in providing shape and encouragement within the initial phases of the project

Kirsten and Sidney Shain, mother and father, for your continued motivation and encouragement to carry out the research and writing, and for providing your home as a much needed retreat where I was well-fed while I worked

Marcie Dorothy Ryan, my lover and partner in life, for your patience, your continued excitement and your pragmatic advice throughout the project, and most of all for your love and companionship that you give to me each and every day 


\section{DEDICATION}

To all the artists, activists, scholars and lovers of the arts who devote time and energy to supporting and promoting the Disability Arts and Culture Movement. 
TABLE OF CONTENTS

ABSTRACT

ACKNOWLEDGMENTS iv

DEDICATION v v

TABLE OF CONTENTS $\quad$ vi

$\begin{array}{ll}\text { CHAPTER ONE: INTRODUCTION } & 1\end{array}$

CHAPTER TWO: THEORETICAL APPROACH 14

CHAPTER THREE: LITERATURE REVIEW 32

$\begin{array}{ll}\text { CHAPTER FOUR: METHODOLOGY } & 48\end{array}$

$\begin{array}{lr}\text { CHAPTER FIVE: ANALYSIS } & 57\end{array}$

$\begin{array}{ll}\text { CHAPTER SIX: CONCLUSION } & 99\end{array}$

$\begin{array}{ll}\text { REFERENCES } & 112\end{array}$

$\begin{array}{ll}\text { APPENDIX A } & {[1-10]}\end{array}$ 


\section{CHAPTER ONE: INTRODUCTION}

It moves us, impassions us, emboldens us. Disability Art - for many of us, the stuff and business of our everyday and particular lives. But let's not underestimate the power of what has happened here in the past three days. Disabled artists and creators... have pushed back the demons of shame and humiliation ... have wrenched the cameras away from the distorting angles of mainstream media ... have bitten a goodly chunk or two out of the benevolent hand of charity.

(http://www.s4dac.org/festivals/kickstart/2004/catherin e_frazee_keynote.html)

Catherine Frazee made the above comments at Kickstart2 - the second international disability arts festival held in Vancouver, British Columbia, in September 2004. This three-day event featured poetry, theatre, dance, comedy, music as well as painting, sculpting and photography. It brought together disability artists from across Canada and around the world.

Across Canada there have been similar types of events over the past five years. The first Kickstart festival occurred in August, 2001, also in Vancouver. Every July, since the summer of 2000 , the Disability Studies department at Ryerson University has been holding an evening of live performance. The Calgary SCOPE Society, which provides support to enable people with developmental disabilities to live in the community, has held four 'Picture This' festivals featuring international disability films since 2001. Several of their projects have used video and performance in organizing people with developmental disabilities to speak 
out on personal and social justice issues. ${ }^{1}$ Stage-Left Productions, also based in Calgary, has hosted four performing arts festivals between 2002 and 2005. Stage Left Productions engage in professional artist - community collaboration. They "practice a highly specialized, socio-political performing arts model made up of Popular Theater and Theatre of the Oppressed techniques, coupled with interdisciplinary Performance Creation, to genuinely affect personal and social transformation in marginalized communities." (http://www.stageleft.org/StageLeftMain.htm) ${ }^{2}$ The Canadian Abilities Foundation held a disability film festival in June 2004 and a performing arts festival in the fall of 2005, both in Toronto.

Several Canadian disability artists are known on the national and international levels. These include comedians Gord Paynter and Tyler Fortin, dance artists Spirit Synott and France Geffory, and theatre artists Alix Blume and Victoria Maxwell. As well, companies such as Theatre Terrific in Vancouver, training programmes such as Dance Ability in Ottawa, and exhibit halls such as the Creative Spirit Centre in Toronto support the on-going development of the work of disability artists. ${ }^{3}$

This growth in disability arts events and festivals over the past five years is a new feature on the Canadian disability scene. Although past disability conferences

\footnotetext{
${ }_{1}^{1}$ For more information, please see www.calgscope.org.

${ }^{2}$ For more information, please see www.stage-left.org.

${ }^{3}$ For a more complete listing of disability artists and disability arts organizations, please see www.stageleft.org.
} 
and conventions have included artists in their focus on the struggle for Human Rights and equality ${ }^{4}$, disability arts festivals represent a different type of event. These are arts events first and foremost, focusing on the artistic merits of the exhibits and performances, and on how this art translates into an expression of an emerging disability culture.

This present study is very much intertwined with my own identity as a disabled person, as a student of Social Work as well as a disability artist. For the past 16 years l've been performing both stand-up comedy and theatre, touring professionally across Canada and around the world. I've attended several disability arts festivals and have met disability artists such as David Roche in California, Philip Patson in New Zealand, Mat Frazer in England, and Tony Doyle in Australia. These performers are all powerful forces within the international Disability Arts and Culture Movement.

My work in comedy and theatre primarily focuses on the physical and attitudinal barriers which I face as a disabled person. I find that humour provides a bond between the audience and the performer. It enables me to 'attack' the audience's own perceptions of disability without alienating them. Comedy provides a sense that I am sharing my experiences with them, and that we are laughing at 'those

\footnotetext{
${ }^{4}$ For example, both Independence ' 92 in Vancouver, and Access to Independence held in Halifax in 1995 were landmark events for the Canadian disability movement. These conventions brought together activists, policy-makers, and service-providers.
} 
people out there.' This experience has taught me how comedy and theatre enables me to tell my own story from a position of power.

Deciding to do my MSW was as much of an attempt to understand my own life, and my place in the world, as it was to develop a set of analytical and practiceskills. As a disabled person 1 knew the experience of marginalization and powerlessness first-hand. I had wanted to explore the necessary changes to policies and practices which would create a social world more inclusive to Disabled Peoples. While doing my MSW degree, I continued to write and perform stand-up comedy and theatre.

In 1999 I wrote and performed a one-person, one-act play entitled Still Waiting for That Special Bus in the Ottawa Fringe Festival. ${ }^{5}$ This play was so successful that I toured it across Canada the following summer, and was invited to perform it in the 2000 Paralympics Art festival in Sydney, Australia. ${ }^{6}$ Since that time I have performed this play at various festivals as well as in schools and at conferences.

There were several reasons why I chose to write this play. I wanted to show people a 'slice' of my life on my own terms. I also wanted to counter the stereotypical use of disability within theatre. More often than not, the dramatic

\footnotetext{
${ }^{5}$ Fringe festivals are non-juried theatre events which occur in several different cities across Canada each summer. They offer a space for new, as well as seasoned actors and writers to explore new and innovative works.

${ }^{6}$ The Paralympic games are the largest international competition for disabled athletes. They occur every four years and are held immediately following the Olympics.
} 
focus is on the particularities of that person's disability to the neglect of their social circumstances. This locates the struggle within the individual and how they deal with their functional limitations, which frames the disabled character as either a victim or a hero of their own circumstances (Lewis 2000; Morris 1991). I feel these types of portrayals continue the oppression I face in my daily life as a disabled person.

The goal of the structural approach to social work is to produce change at both the structural and individual levels. Maurice Moreau argues that the role of the worker should be assist individuals to 'unmask and name their oppression', along with working towards changing structures which reproduce inequality (Moreau, 1990). Moreau distinguishes between primary and secondary 'pillars of oppression.' Primary pillars operate on a macro level, and are based on patriarchy, racism, and capitalism, which are intersected with ablism and ageism. These structures have a greater impact on reproducing inequality within people's lives than the secondary pillars which include personality, family, economics, and bureaucracy. Moreau argues that these different layers of oppression are experienced alongside each other, and it is the interweaving of these structures which construct an individual's experience of a particular reality.

The writing and performing of the play was my way of naming my oppression. I also believe the play has a role in affecting structural change. This current examination of Still Waiting for That Special Bus is inspired by the fact that I 
consider myself a disability activist who is doing theatre. I wanted to answer the question as to how I see myself as intervening into structural relationships surrounding ability and power. This implied a relationship between theatre and social protest.

\section{STATEMENT OF THE PROBLEM}

Disabled Canadians are over-represented when it comes to living in poverty as well as experiencing violence and abuse. They often face barriers within major life areas such as employment, education, housing, transportation, or culture and recreation. Within North America, the Independent Living Movement has politicized disability issues as a struggle for Human Rights and equality by engaging in political action and debate. This has involved challenging dominant frameworks which individualize disability, resisting relationships of passivity and charity, and demanding choice and control for disabled Canadians.

The struggle of attaining equal rights and freedoms for Disabled Peoples has included a struggle over meaning and identity. What does it mean to have a disability? Is this a positive or negative label? These types of struggles over a collective identity are both personal and political in the same way as it has been for the Women's Movement, the Gay Liberation Movement and the Anti-Racism Movement. Each of these social movements has bred their own culture of 
resistance. Through collective action and protest, people within the movement find their own voices, their own stories, their own method of sharing these stories and shaping their identities.

The struggle of Disabled Peoples for Human Rights and equality frames disability as being socially constructed, rather than being solely defined by mental and physical limitation. Stephen French Gilson and Elizabeth Depoy put forward that disability is the result of "the interplay of diverse human conditions with environmental barriers to full community inclusion." (2002:153) This places as much emphasis on social structures as on physical and mental functionality for creating inequality. While it is acknowledged that individual limitations may cause disabilities, they don't do so just by themselves, but only through interacting with environmental barriers. Gilson and Depoy go on to say that "this contemporary view of disability, although consistent with the mission and values of social work, receives limited attention in social work curricula." (ibid)

The aim of this current study is to add to the growing effort within social work research and practice to incorporate a better understanding of disability oppression by examining arts and culture as a site of struggle for equality and Human Rights. Mainstream images of disability often represent weakness, ugliness, despair, and evil (Thomson 2000; Covey 1998; Norden 1994; Hevey 1992). This type of imagery affects the lives of Disabled Peoples. As Jim Ferris writes: 
[l]t is asking too much to say to one identified [as a disabled person] that physical disability means emotional cripple, but it only means that in art, so don't take it personally. My body is personal, and as feminism has recognized, the personal is political. ( $p$. 508)

Feminist Movements within North America and England have incorporated art into the struggle against gender oppression. This has been to challenge dominant cultural definitions of strength and autonomy which devalue the experiences of women. In much the same way, the Disability Arts and Culture Movement has begun challenging dominant cultural notions of beauty, strength and independence which devalue the experience of disability. ${ }^{7}$

Disability artists typically explore issues around identity, collectivity and political struggle. As such, they are framing disability in ways which challenge dominant paradigms. The main purpose of this study is to understand the significance of the Disability Arts and Culture Movement to the Human Rights and equality of Disabled Peoples. A growing body of research is now examining the ways in which Disabled Peoples themselves are countering dominant narratives of disability through the arts (Abbas et al. 2004; Barnes, Mercer and Shakespeare 1999; Darke 1998, 2004; Fries 1997; Hevey 1993; Longmore 1995; Sandahl 1999, 2002; Swain and French 2000; Walker 1998). By incorporating this

\footnotetext{
${ }^{7}$ By drawing this comparison between Feminism and the struggle against disability oppression I am not suggesting that Feminist movements have been inclusive to Disabled Peoples. To the contrary, until very recently, discussions around disability have been excluded by Feminist theory and practice. As a result, disabled women have felt largely left out of the larger struggle against gender oppression. (Odette, 1993; Meekosha, 1998; Wendell, 1997)
} 
growing body of research on disability arts through the analysis of my play, Still Waiting for That Special Bus, social work can begin to understand:

i) how cultural notions of disability oppress and silence the voices of Disabled Peoples;

ii) how Disabled Peoples are shaping their own stories and identities, and

iii) the linkages between Disabled Peoples' oppression and social work education, training, research and practice.

My work as a disability artist who is studying social work provides the opportunity to examine the intersection of theatre and the struggle against oppression. It is my hope that this research will provide a deeper understanding of the experience of disability as well as the role of the arts in framing that experience. The aim of this is to encourage a more reflective practice with respect to supporting Disabled Peoples.

\section{RESEARCH QUESTIONS:}

1) What is the relationship between arts and culture, and the struggle for Human Rights and equality? 
2) What are the dominant narratives surrounding disability?

- What have been the political implications of these dominant narratives for Disabled Peoples?

3) What is the political significance of the Disability Arts and Culture Movement to the struggle for Human Rights and equality for Disabled Peoples?

4) How does my play break dominant narratives surrounding impairment and disability?

5) What are the implications for the development of anti-oppression theory, policy and practice in supporting Disabled Peoples?

\section{ORGANIZATION OF MATERIAL BY CHAPTER}

Chapters II and III lay the theoretical groundwork for the way I'm approaching my play as a means to address disability oppression. In Chapter II a framework is developed for analyzing art as political intervention, with a particular focus on theatre. I also discuss the Independent Living paradigm and the social model of disability, which are at the core of the politicization of disability issues. Particular attention is paid to literature on the issues affecting disabled Canadians. 
Chapter III will review the literature on the significance of disability arts to the politics of disability. My focus will be on the ways in which the Disability Arts and Culture Movement is founded upon the social model, with particular attention how the arts carry forward Disabled Peoples' struggle for equality and Human Rights.

Chapters IV and V deal with the treatment of my play Still Waiting for That Special Bus. In Chapter IV, I present a detailed description of the methodology I am using to analyze my script. Attention will be paid to the strengths and weaknesses of my design. The next chapter will present an analysis of my play, connecting the findings to themes arising from the literature on disability arts. Implications for research, policy, education and practice, discussed within the last chapter, will be reflexive in nature. I will discuss the importance of the social model in understanding disability oppression and working with Disabled Peoples.

\section{REDEFINING DISABILITY TERMINOLOGY}

My study makes a crucial difference between bodily impairment and socially constructed disability. Impairment refers to the mental and physical limitations of individuals, while disability refers to the set of structural arrangements which oppress people based on impairment. ${ }^{8}$

\footnotetext{
${ }^{8}$ People who are deaf often view themselves as seperate from the disability movement, seeing themselves in terms of a lingustic minority. There is also a distinction made within the disability movement between physical disabilities, and mental, psychological and learning disabilities. For example, the Independent Living Movement within both Canada and the United States has primarily focused on issues affecting
} 
Following from this, I have chosen to use the term Disabled Peoples to symbolize that structural relationships which oppress impaired people do so across class, gender, age, sexual orientation, race and ethnicity. Thus, I want to acknowledge that Disabled Peoples includes impaired people from different socio-economic and cultural backgrounds.

It is important to acknowledge that, within the literature, the terms people with a disability, people with disabilities, and disabled people are all used to refer to persons who are oppressed on the basis of impairment. Within North America, the term 'people with disabilities' has received preference to symbolize that impairment is only one aspect of the entire person. Within England, the term most commonly used is 'disabled people' to symbolize that 'it is society which disables physically [and mentally] impaired people. Disability is ... imposed on top of ... impairments" (from the Fundamental Principles document, the Union of Physically Impaired Against Segregation and the Disability Alliance, quoted in Oliver 1996:20)

I have endeavoured to maintain a clear distinction between impairment and disability throughout this thesis. While the term people with disabilities may appear in this paper, it is only because this is used by the author from which I am quoting. While I acknowledge that these two terms refer to the same concept, I

people with physical impairments, while the People First Movenment focuses on issues affecting people with intellectual impairments. 
believe that the use of people with disabilities confuses the distinction between impairment and disability.

My use of disability artists, and the Disability Arts and Culture Movement follow from this understanding of impairment and disability. The term 'disability artists' is used to refer to artists who incorporate impairment and disability into both their identity and their work. These are artists who see their work as emanating from the struggle for the equality and Human Rights of Disabled Peoples and who consciously identify themselves with the Disability Arts and Culture Movement.

Throughout this thesis I use Disability Arts and Culture Movement, disability arts, and disability culture interchangeably in discussing a growing international movement of artists whose work explores different aspects of disability identity. This body of work spans all creative mediums within the literary, visual and performing arts. 


\section{CHAPTER TWO: THEORETICAL APPROACH}

Augusto Boal (1979) sees theatre as the most important art form in enabling people to name their oppression and challenge dominant power structures. While his focus is on class struggle, I believe his analysis and theatre practice is useful for understanding disability theatre. Amy Mullin (2000), in her discussion of Feminism and art, illustrates the power of artworks to engage the viewer in critical debates around gender and identity. I will draw on her argument in order to place disability arts within the same context of a politicized struggle for identity. The deconstruction of disability inequality, as with gender inequality, incorporates an analysis of power and institutionalized practice. In the last part of this chapter, I will outline the social model of disability and the politicalization of disability issues within Canada.

\section{THEATRE AS A SITE OF POLITICAL STRUGGLE}

Within the art world, it is still highly contentious to claim a connection between art and politics. Boal notes that this debate is as old as art and politics themselves. He writes that "On one hand, art is affirmed to be pure contemplation, and on the other hand, it is considered to present always a vision of the world in transformation and therefore is inevitably political insofar as it shows the means of carrying out that transformation or of delaying it." (1979:xiii) 
In discussing Feminist art, Amy Mullin reviews these same debates among art theorists. On one side of the continuum is the perspective that the creation, production and experience of art occurs outside social and political forces. Artists are individual geniuses and their work is not affected by their surroundings. Furthermore, the critique of art should not be affected by moral or social implications. Art should be evaluated entirely based on its form. The content of a particular piece or work is only secondary, and can actually impede on the true appreciation of the work. This viewpoint, Mullin argues, divorces the content of the artwork from its formal properties, meaning its style, its tradition and format.

As a result, even those theories that acknowledge that a work of art may be evaluated morally, as well as aesthetically, miss the unique contribution that artworks may make in initiating an encounter in which we are receptive to the work in a non-rulebound manner ... [A]rtworks, including feminist artworks, are valuable because of the way we respond to art with our senses, emotions, imagination, and understanding, all in interplay. A feminist artwork is not separable into two distinct aspects: an artwork, which provokes a purely sensuous response, and a political lesson, which we cognitively process. All of the aspects of the work, its formal properties, the emotions it invokes, and the ideas it suggests, work together. (2000:126-127)

This corresponds to the way I am approaching disability theatre. As I will discuss more significantly below, that Disabled Peoples are creating and producing art is political not only in its content but also in its style and form. In other words, the impact of disability theatre lies not only in what is being said, but also in how it is being said. 
The political importance of art is highlighted by Murray Edelman (1995). In his view, politics cannot exist without art. Political action and public ideology rests upon the ability to evoke certain types of narratives, ideals and images, all of which stem from art. The ways in which current events are interpreted are "social capital, not individual inventions [coming] from works of art in all genres: novels, paintings, stories, films, dramas, television sitcoms, striking rumors, even memorable jokes." (p. 1) Edelman's discussion includes everything from classical theatre and painting, to modern-day film and television. Thus, he argues that the rise of literacy and mass media has increased, rather than decreased the role of art in shaping political ideology.

However, it is always the public ideology and political climate of the day which take specific political meanings from works of art (p. 7). For example, Edelman claims that though our ideas and perspectives about women come more from art than from everyday encounters, there exists a wide range of images of women as being both strong and weak, and as both subservient to and more powerful than men. Even when these contradictory messages appear, political leaders ${ }^{9}$ and public ideology can frame works in order to uphold the ideals of their own choice, thereby shaping audience response. Furthermore, Edelman points out that the political influence of art is not related to its quality, but rather depends upon how well particular works draw upon popular fears and sentimentalities.

\footnotetext{
${ }^{9}$ By political leaders Edelman is referring both to those who hold dominant power (i.e. holders of political office) as well as those who are challenging dominant power (i.e. leaders within political movements) .
} 
Edelman illustrates how new artistic movements tend to arise when there is a growing disillusionment in dominant political beliefs and values. He particularly notes the role of beauty in stating that much of twentieth century art has focused on the ugliness of everyday life.

Disharmony and unattractive appearance can be a commentary on, or a criticism of, the disorder and unpleasant ambiance of contemporary society and government. To depict the world as beautiful is to presuppose that its basic institutions can be ideal in principle even if they fall short in practice. But a considerable amount of twentieth-century art implies or proclaims that disharmony and its unpleasant concomitants are innate. In conveying that outlook, these works may also encourage examination of the specific social practices and institutions that are to blame. (p. 23)

Within this type of framework, theatre can be analyzed as political intervention into shared understandings, values, and beliefs. It presents a particular construction of reality. Boal argues that dominant art forms reflect the ideology of the dominant classes. Theatre is a weapon that yields political ideas and ideologies which can either repress or liberate oppressed peoples. The dominant classes have attempted to control the means of cultural production because of the power of art in framing both personal and political realities. New forms of theatre must be created which reflect the experiences of oppressed peoples. In this sense then, theatre becomes a mobilizing force for change, serving as a way for people to analyze and name their oppression. I am placing disability theatre within Boal's context of a revolution, arguing that it is an effective means of both 
challenging the dominant structure of social relations as well as outlining a course for political action.

Similar to Boal's analysis of class oppression as being embedded within the very art forms themselves, David Hevey (1993) traces the problem of disability representation back to the form of The Greek Tragedy. Disability represented the social flaw that needed to be purged for the good of broader society. For example, the story of Oedipus is about a king who is unaware of his own wrongdoings (killing his father and sleeping with his mother). Thus, "Oedipus blinds himself to make physical that which is fate. ... He paid for his transgressions by becoming disabled." (p. 424) The representation of disability as impairment and social flaw unites "practically the entire discourse, from Greek Theatre to James Bond Villains to Charity Advertising to all the Richard III's" (ibid). New cultural forms need to be created which not only shift physical impairment away from social disability but also shows the process by which this occurs. In arguing that the act of showing must also be shown, Hevey writes:

This is to acknowledge that the representational forms themselves are conveyers of messages but are not innocent of the struggle. The point of new methods with new messages is that they convey the sense of a new order (or at least the decline of the old one). ( $p$. 428)

The work of disability artists inherently challenges dominant structural relations surrounding disability. Visual artist Mandla Mabila in South Africa, places disability art and performance within the context of the struggle for disability rights. 
Art is a political tool in that when disabled people represent themselves they are going against the tradition of being represented by others. The political power is in determining not only who we are but who we can be on our own terms and art provides this possibility. (quoted by Barry, 2002)

Mabila believes that art plays a crucial role in attaining disability equality. His discussion covers not only challenging negative disability imagery, but also challenging the inaccessibility of art and cultural institutions. While there are many disability artists creating good work, he argues they are having minimal effect within mainstream arts. He sees this changing only through Disabled Peoples occupying "key" positions within arts and cultural institutions. Mabila is addressing the existing set of structural relations surrounding cultural production which exclude Disabled Peoples. He is making a link between art and dominant relations of power. Disability arts embody the struggle for Human Rights and equality which are the goals of the broader disability movement.

Boal is important for my analysis because of his focus on theatre. His book, The Theater of the Oppressed (1979) is essentially a handbook for revolution, outlining the use of theatre as a means to dismantle dominant power arrangements. Boal sees this as occurring by dismantling the barriers that have been established between actor and spectator, and between protagonist and chorus. Not only do these divisions restrict who is allowed to be on-stage, but also the direction and intention of dramatic action. For Boal, theatre can function as a rehearsal for revolutionary change wherein oppressed peoples can explore the actions which can bring about structural change. 
Taking control over artistic production, then, implies transforming established divisions between actor, spectator, protagonist and chorus. As I will describe in the next chapter, disability artists are challenging a set of structural relations which have cast Disabled Peoples into roles reflecting passivity and charity. Challenging dominant power structures is an essential part of the struggle for disability rights and equality. On one level, Boal's approach means that Disabled Peoples must be directors and producers as well as actors. Yet it cannot be a simple matter of inserting Disabled Peoples into these positions of power. These roles are defined by the dominant set of structural relations which exclude people on the basis of physical and mental ability. When Boal says everyone must act and be a protagonist, he is advocating the dismantling of the dominant structure of social relations which give people authority over the actions of others. In Boal's schema, gaining control over the means of cultural production transforms the very nature of power relations themselves. Thus, disability artists are necessarily engaged in a political struggle for social justice and equality.

\section{THE POLITICS OF DISABILITY}

I. Defining disability and impairment

According to Statistics Canada (2003), there were 3.6 million disabled Canadians in 2001 . This constitutes $12.4 \%$ of the population. Putting this in perspective, in the same year $13.4 \%$, or almost four million Canadians reported belonging to a visible minority group. (Statistics Canada 2003) Thus, the proportion of disabled Canadians is significant. 
These figures on disabled Canadians cover people with physical, intellectual and psychiatric and learning impairments. Most common among adults aged 15 and over are mobility impairments, with 2.5 million reporting difficulty walking, climbing stairs, or moving from one room to another. It is important to remember, however, that it is common for people to report having multiple impairments. Thus, for example, a person might report being affected in terms of both their learning and mobility. This means they would be counted within both impairment groups. Thus, these categories are not mutually exclusive. Impairment also cuts across class, gender, age, sexual orientation, race and ethnicity. Thus Disabled Peoples are not a uniform group. For example, among adults aged 15 years and over, there are a greater proportion of women $(15.7 \%)$ who report being disabled than men $(13.4 \%)$.

Disabled Canadians have significantly lower educational, employment and income levels than the general population. In $2001,37 \%$ of disabled adults aged 15 to 64 had less than high school as their highest level of education. A further $23 \%$ had only high school, and $11.4 \%$ had attained a university degree. For nondisabled adults, $25.3 \%$ had less than high school, $26.8 \%$ had high school, and $20.4 \%$ had a university degree as their highest level of education.

Within the labour force, only $41.5 \%$ of disabled adults were employed, versus $73.8 \%$ of the non-disabled population. Forty-nine percent of disabled adults were 
not in the labour force, versus only $20.6 \%$ of non-disabled adults. This translates into much higher poverty rates among Disabled Peoples. Thirty-eight percent had an income under $\$ 10,000$, versus $29.7 \%$ for non-disabled adults. Thirty thousand dollars is considered a comfortable annual income for the average Canadian, yet only $26.3 \%$ of disabled adults earned this in 2001 in contrast to $40.2 \%$ of nondisabled adults.

The interpretation of the above data is not straight-forward, but varies greatly according to the theoretical approach to impairment and disability. These different explanations can be arranged along a continuum with the individual model and social model at opposite ends. On the one hand, the individual model defines being disabled in terms of an individualized problem. Lower levels of education, employment and income are framed as a direct result of mental and physical impairments.

On the other end of the continuum, the social model sees disability as being constructed by the political, economic and cultural make-up of society. Crucial to the social model is the distinction made between physical and mental impairment and socially constructed disability. While impairment refers to differences in mental and physical functionality, disability refers to the institutional arrangements and practices which disadvantage people based on impairment. However, there is no causal link between disability and impairment. This can be understood in much the same way as the difference that Feminist theory and 
practice makes between biological sex and socially constructed gender. Gender inequality is framed as being the result of institutionalized practice and oppression, and is not directly linked to the biological differences between men and women. Thus, disability is a consequence of social oppression, not of impairment. This does not deny the existence of functional impairments. But the social model does deny that these functional impairments necessarily lead to lower social status.

The approach used by Statistics Canada to measure disability lies somewhere between these two ends of the continuum. It is based on the International Classification of Functioning, Disability and Health, from the World Health Organization. The ICFDH makes a distinction between impairments, activity limitations and participation restrictions (WHO 2001). Impairment refers to an individual's functional characteristics, such as seeing, hearing or learning. Activity limitations refers to the difficulties a person may have with daily tasks, such as eating and dressing, or reading and writing, resulting from an impairment. Participation restrictions typically refer to the broader social roles of an individual, such as attaining education and employment.

Using the ICFDH framework, Statistics Canada measures disability as "the interrelationship between body functions, activities and social participation, while recognizing the role of the environment as providing barriers or facilitators." (Statistics Canada 2001:17) This allows for the measurement of impairment, 
activity limitations and participation restrictions independent of one another. Disability is not based on medical diagnoses, but rather on the interplay between the individual and their environment. Impairment to body functions does not necessarily lead to activity and participation limitations. The sociopolitical environment may either prevent or facilitate participation. Statistics Canada gathers information on access to disability-related supports, such as adapted equipment or attendant services. A person's use of a wheelchair or a Seeing Eye dog may eliminate many activity limitations, yet they may still be restricted in areas of employment and education due to discrimination. Thus, the sociopolitical environment plays a significant role in the ways in which impairments affect an individual's life.

The social model underlies the Independent Living Movement within North America, and the Disabled People's Movement in England. Lower levels of employment and education are framed in terms of institutional and architectural barriers instead of being the result of personal limitations.

\section{The politicization of Disabled Peoples}

Over different historical time-periods within western culture, Disabled Peoples have been the object of power and control. Roy Hanes points to the considerable amount of research showing how notions of disability have been underpinned by such things as "possession of an evil spirit; punishment for sin, as a medical problem; as a social welfare category and as a civil rights issue" (2002:222). As a 
result, western society has managed Disabled Peoples in differing ways according to these beliefs by "religious zealots, shamans, magistrates, administrators of poorhouses and asylums, as well as charity aid workers" (ibid).

Gillian Fulcher (1989) presents the analysis that welfare states have created the disability category in order to regulate individual need. This category is used to determine who is disabled, how disabled they are, and how institutions should respond. The use of medical discourse depoliticizes disability by relegating it to the human body. "For disabled people the body is the site of oppression, both in form and in what is done to it" (p. 114). As I will discuss later, disability arts often use the body as crucial to the expression of a disability identity. Perceived control of one's body is central to our western culture. Fulcher argues that "[w]e should theorize the oppression that present practices construct around disability in terms of their support for the moral order and for the objectives of capitalists." (p.43) Challenging social practice means challenging the power of the State to define and control who is and who is not disabled, and what people are entitled to.

Deborah Stone (1984) discusses the concept of a moral economy where paid work is seen as the only legitimate economic activity. She analyzes disability as representing 'need, help, and privilege.' It has been a way for the state to distinguish between the 'deserving and the undeserving poor.' Defining disability as being unable to work, justifies the low living standards and minimal access to rights that are accorded to Disabled Peoples. 
Michael Oliver (1996) argues that service provision based on individualized needs has socialized Disabled Peoples into a role of passive citizenship in order to receive services. The state determines what their needs are and how best to meet these needs. This has led to intrusions into peoples' lives to determine their level of need. "[A]ssessment of need is an exercise in power." (p. 70) Services are provided for Disabled Peoples rather than by Disabled Peoples. "Given this proviso, it is nonetheless rights to appropriate welfare services to meet their own self-defined needs that disabled people are demanding, not to have their needs defined and met by others." (p. 74)

Each one of the above theorists approaches disability as a category of oppression. Ronald Mackelprang and R. Salsgiver argue that the Independent Living framework and corresponding movement represents a minority rights model for Disabled Peoples (1996:10). According to this model, Disabled Peoples are theorized as a socio-cultural group alongside racial and ethnic minorities. Group inclusion is based on self-identification as a disabled person instead of being based upon a medical diagnosis. It is the sharing of common experiences, beliefs and values that unite Disabled Peoples. Disability is not seen solely in terms of a denial of rights, but also in terms of a group identity based on common experiences. The minority rights model redefines the focus of intervention. Instead of changing individual circumstances, intervention is directed at changing the social, economic and political factors which disable the 
individual. Services would not be organized around individual need or medical criteria. The barriers to be addressed would include "negative attitudes, limited or nonexistent physical and communication access, and the denial of rights and privileges" (Gilson and Depoy 2002:156).

A monumental achievement for the Canadian Independent Living Movement was the inclusion of disability within the 1982 Charter of Rights and Freedoms. Disabled Canadians became recognized as one of the designated groups for affirmative action and protection against discrimination. This signified a fundamental change in the approach to disability. No longer was the segregation and inequality of disabled Canadians framed solely in terms of impairment. Rather, their experiences were at least partially framed in terms of physical and institutional barriers. This followed the publication of Obstacles Report in 1981, which documented that disabled Canadians were discontent with having to rely on segregated services. They were framing segregation as being the root cause of their inequality and demanding a new social relationship to Canadian society based upon inclusion. This was to be predicated upon active involvement and personal choice (Gadacz 1994).

A key concept within the Independent Living framework is that of control, Disabled Peoples should be able to direct supports and services according to their own life-style choices. Thus. systems of service-delivery must be flexible according to individual need. The Independent Living framework rejects eligibility 
for supports and services being defined according to functional limitations and individual need. Instead, these needs are defined in terms of rights to full citizenship. To this effect, the Independent Living Movement has focused on peer support, rather than professional intervention. A slogan coined by the Independent Living framework is that the disabled individual is the expert which refers to the concept of self-help and Disabled Peoples.

Independent Living Centres (ILCs) represent the process of connecting people with differing impairments with one another in order to determine what their own needs are and how these needs should be met. Cross-disability organizing and community-building has been the cornerstone of the Independent Living Movement, in part to resist the defining of disability along medical lines and grouping individuals according to biological conditions. The medicalization of disability is seen as fragmenting the disability population and de-politicizing their issues. "The overall goals of the movement are to challenge and end these efforts of domination, to reclaim expropriated bodies and to re-appropriate the spoiled identities that are a result of ... medical and rehabilitation practices, misguided public policies and programs, bad laws and legislation and paternalistic attitudes." (Gadacz 1994:9)

David Cameron and Fraser Valentine (2001) argue that despite the political movement of the Disabled Peoples, Canadian social policy has not undergone any radical changes in the way that disability issues are approached. They claim 
that much of disability policy has been, and continues to be developed under the assumption that Disabled Peoples are segregated from the rest of society. Despite the passage of the Charter of Human Rights and Freedoms 25 years ago, disabled Canadians still face enormous inequality within education, employment and income, While there have been some gains in terms of rightsbased claims to equality, general social and economic policy needs to be made much more inclusive of disabled Canadians.

According to Sheri Torjman (2001), while Canada officially recognizes the WHO classification of impairment, activity limitations and participation restrictions, many Canadian programs employ much stricter definitions of disability in order to restrict eligibility. These types of supports include attendant services, technical aids and equipment, tax credits, specialized welfare provisions, employment assistance, and social insurance programs (such as worker's compensation, employment insurance and the Canada/Quebec Pension Plan). All of these programs focus on providing services to individuals as opposed to securing equality rights for disabled Canadians.

Gilson and DePoy (2002) raise the concern that social work research, education and practice frames Disabled Peoples as a "population at risk." They argue that this devalues the disability experience. It implies a "failure in one or more essential life functions" necessitating "services and protection from 
professionals." (2002:157) To be disabled within this type of framework can only be a problem.

Through theatre and other forms of art, Disabled Peoples are exploring new theoretical avenues towards understanding disability, as well as new forms of political and social action in attaining disability equality. John Swain and Sally French (2000) suggest that a different type of model is emanating from the Disability Arts and Culture Movement, which they tentatively label the Affirmative Model. They note that sociological theory rarely validates the disability experience. Non-disabled people basically accept the social model "albeit superficially and on a basic conceptual level" (p. 570). Much more threatening and challenging for many people is the notion of a disabled person as being pleased and proud to be the person who they are.

We are at a significant point in history where Disabled Peoples are organizing for themselves and challenging dominant power structures. No other historical time period has seen such widespread politicization of disability issues. Simi Linton writes "We are all bound together, not by [a] list of our collective symptoms but by the social and political circumstances that have forged us as a group. We have found one another and found a voice to express not despair at our fate but outrage at our social positioning." (1998:4) Paul Longmore (1995) argues that to continue the individualized analysis of disability is to continue the oppression of Disabled Peoples. To place all of this in Boal's terms, Disabled Peoples are 
becoming actors and protagonists in social change. Swain and French argue that the Disability Arts and Culture Movement has a crucial role to play for theory, education and practice as a way to both validate the disability experience and to become more of an ally in the struggle against disability oppression. 


\section{CHAPTER THREE: LITERATURE REVIEW}

The literature on the Disability Arts and Culture Movement has grown significantly over the past 15 years. In reviewing major themes, my focus will be on its sociopolitical significance. Jihan Abbas, Kathryn Church, Catherine Frazee and Melanie Panitch (2004) state that, while countering traditional imagery of Disabled Peoples is an important element, the real focus and power of disability arts is in producing work which eminates from the disability experience. My aim at this point is to only highlight the political importance of the Disability Arts and Culture Movement. My analysis chapter will deal with the strategies of representation employed by theatre artists with special attention to the ways in which impairment and disability are being deconstructed and reconstructed within disability arts.

A significant area of discussion which I won't be touching on is the level of resources accessible to disability artists. This type of support, however, is crucial to the impact of their work. Abbas et al. state that, in the course of their research on the status of disability arts within Canada, there wasn't a single funding source that specifically addressed the needs of disability artists (p. 47). This is highly problematic when considering that disability is still largely individualized. The work of disability artists is often viewed as potentially contributing to therapy and education rather than in terms of their artistic and cultural implications. Abbas et al. argue that this leaves disability artists outside of the mechanisms of arts-based funding. Ironically the majority of disability-related funders also do not 
view disability arts as being within their agenda (Mitchell and Snyder 2000). However, I feel these funding issues involve a separate discussion and are directly related to the minimal level of support that arts and culture generally receives within our culture.

\section{LACK OF VOICE WITHIN THE MAINSTREAM}

A prominent discussion occurring within the literature on disability arts is over the lack of voice of Disabled Peoples within mainstream arts and culture. Abbas et al. begin their report on disability arts within Canada by saying, "we find ourselves confronting a reality in which the voices, experiences, and struggles of disabled people are either strikingly absent, or grossly and stereotypically misrepresented in mainstream art." (2004:5) Jenny Morris, writing in England over a decade ago, argues that there is an essential connection between the lack of voice within arts and culture, and a lack of theoretical space for Disabled Peoples within academic research and discourse.

Disabled people - men and women - have little opportunity to portray our own experiences within the general culture, or within radical political movements. Our experience is isolated, individualised; the definitions which society places on us centre on judgements of individual capacities and personalities. This lack of a voice, of the representation of our subjective reality, means that it is difficult for non-disabled feminists to incorporate our reality into their research and their theories, unless it is in terms of the way the non-disabled world sees us. (1991:8) 
However, despite the lack of voice given to Disabled Peoples, disability continues to be a common theme within mainstream arts. Victoria Ann Lewis writes "it is not that the nondisabled theater world knows nothing about disability and is waiting to be enlightened. To the contrary, the depiction of disability is over-represented in dramatic literature." (2000:93) She notes how Oedipus and Richard III are stigmatized through disability, and how Tiny Tim is used to represent innocence and goodness. More modern examples include Ron Kovik in the film, Born on the Fourth of July (1990) where disability is used to represent an individual's triumph over seemingly impossible situations (Morris 1991:84-116). David T. Mitchell and Sharon L. Snyder (2000) note that "Every would-be superstar gets his or her disability vehicle eventually: Tom Hanks, Holly Hunter, Jon Voight, Gary Sinse, Bette Davis, Joan Crawford, Tom Cruise, Patty Duke, Jane Wyman, Daniel Bay Lewis, Orson Welles, Richard Dreyfus, etc. ad nauseum." (page 198, author's emphasis) This further highlights the widespread use of disability within mainstream arts and the silencing of Disabled Peoples themselves within these depictions.

Common in each of the above representations is the singular focus on the individual's struggle with impairment to the neglect of the broader social context. The experiences of Tiny Tim, Christy Brown, and Ron Kovik are framed in terms of their functional limitations. The storyline becomes a depiction about how they deal with their own particular circumstances. The attitudes which these characters must face are portrayed as being a direct result of impairment. While 
it is recognized that impairment affects social interaction, this is presented as being inevitable, if unfortunate. The systemic, institutionalized oppression that Disabled Peoples face is not considered.

Disability arts are often situated in opposition to mainstream representations. For example, Morris writes "The non-disabled world is much concerned about the causes of disability while the disabled movement focuses on the effects and thus on our common experience of prejudice and discrimination."., (1991:12) When doing media interviews, my own experience has taught me to be prepared for the question 'What happened to you?' This fascination with the origin of disability need not have anything to do with the actual story. In one incident, I was being interviewed on my participation in an anti-war rally. Among the questions about my involvement was the question 'Why was I in a wheelchair?' Choreographer Rachel Gorman's piece entitled Waking the Living was featured in the 2002 Toronto's Fringe Festival of Independent Dance (fFida). The piece consisted of five dancers, one of whom used a wheelchair. Even though the piece itself was not about disability, the question arose, 'Why is she in a wheelchair?' The choreographer responded with 'Because she needs a wheelchair.' This overwhelming focus placed upon the causes of impairment often compels artists to give a medical diagnosis within their own work. For example, autobiographies such as John Callahan's Don't Worry, He Won't Get Too Far On Foot (1990) and Bonnie Sher Klein's Slow Dance (1997) begins with an account of the onset of their impairment. 
Abbas et al. argue that the deconstruction of cultural imagery surrounding impairment and disability is a central focus of the academic discipline of Disability Studies (p.12). Debates around disability representation center upon issues of control and social consequences. To this effect, the Disability Arts and Culture Movement "marks the growing political power of disabled people over their narratives." (p. 1)

Carrie Sandahl aptly writes "No longer compliant objects of the stare, people with disabilities are staring back, claiming the body as a legitimate part of identity, a body whose metaphors and physicality belong to us." ${ }^{10}$ (1999:13) She argues that functional impairment can be theorized and be actualized as a way of experiencing the world. She writes "Disabilities are states of being that are in themselves generative and, once de-stigmatized, allow us to envision an enormous range of human variety - in terms of bodily, spatial, and social configurations." (2002:19)

Staring back or returning the gaze of dominant culture is prominent in Bell Hooks' discussion of art, identity and confronting racism (1995). Her analysis is useful in terms of understanding the significance of the Disability Arts and Culture Movement to Disabled Peoples. Hooks argues that the lack of Black Art (author's term) within mainstream culture is deeply connected to the internalization of white values and representations which dictate expectations about what art is

\footnotetext{
${ }^{10}$ Both Kenny Fries (1997) and Rosemarie Garland Thomson (1997) make reference to Disabled Peoples staring back in their discussion of disability arts and culture.
} 
supposed to be like. This impedes artistic creation which emanates from Black experience. She writes:

Creating counter-hegemonic images of blackness that resist stereotypes and challenge artistic imagination is not a simple task. To begin with, artists have to engage in the process of education that encourages critical consciousness and enables them as individuals to break the hold of colonizing representations. (1995:96)

The same can be said for Disabled Peoples and for disability culture. There is a lack of art being produced by disability artists within mainstream culture. Dominant representations of disability often alienate Disabled Peoples. These images are overwhelmingly based on the use of impairment to symbolize a character flaw, a personal limitation or an impediment to success and happiness. This alienates Disabled Peoples from art, and art from Disabled Peoples. The Disability Arts and Culture Movement represents the growing critical consciousness of Disabled Peoples surrounding art, identity and disability imagery.

\section{INDIVIDUAL EMPOWERMENT VERSUS SOCIAL CHANGE}

Abbas et al. contrast disability arts to art therapy which "individualizes the artistic process and detaches it from a broader Disability Culture." (p. 9) Their report argues that art therapy has been another way in which Disabled Peoples have been segregated and devalued. Disability artists seek to "cure social 
misperceptions" not the individual. While art therapy may have a role to play in supporting individual expression, the advantages of the Disability Arts and Culture Movement are both individual and collective in that "culture creates a context in which individuals can form social identities that counter popular images/narratives of disabled people as tragic, passive and dependent." (p. 4)

Pamela Walker, in Artists with Disabilities: A Cultural Explosion (1998) describes the birth of Disability Arts within the United States as occurring in three stages. The first stage began with "recognizing ourselves as artists in this society that wanted to keep us only in Art Therapy." (p. 3) Political gatherings emanated from the disability movement in which "an attitude of coping became an attitude of changing." (ibid) The second stage involved disability artists developing their own voices within their own communities. Walker claims that the arts movement is now at the third stage - cultural explosion. "We're taking it to the streets and we're doing it in all forms - fine arts, video, performance, dance, written word, computer - Disability Culture is showing up everywhere that creativity is explored." (ibid)

Walker employs the use of the terms 'Disability Arts' and 'Disability Culture' interchangeably. Yet, she also implicitly distinguishes between the two in advocating that we analyze disability identity and culture through the artistic movement of Disabled Peoples:

Disability Culture is made up of artists who are not trying to pass, artists who don't buy into societies rule 
that we should be ashamed of our disabilities, artists who often show in their art a self-acceptance and a pride about who they are, not in spite of a disability, not because of a disability, but including a disability. (p. 5)

Writing in 1996, Michael Oliver and Jane Campbell discuss the growth in the Disabled People's Movement in terms of challenging dominant perceptions of disability, the affirmation of positive images, and the development of a politics of identity (p. 20). The Disability Arts and Culture Movement has also been described in these ways. Disabled Peoples are challenging dominant beliefs and values through the creation of art and performance.

Paul Longmore (1995), for example, argues that the Disability Arts and Culture Movement represents an exploration of a collective identity based on the disability experience. This involves treating the disability experience as being valid and whole, and exploring the values which emulate from this experience. Inherent within the creation of a disability culture is a complete rejection that the disabled individual must overcome impairment and live up to non-disabled norms and ideals in order to be a valued citizen. Longmore cites such self-affirming slogans as "Disabled and Proud", "Deaf Pride" and "Disability Cool" as an illustration of Disabled Peoples "seiz[ing] control of the definition of their identities" to claim their own voices and realities (p. 5). These slogans are to the disability movement what 'Gay Pride' is to the Gay Liberation Movement, or what 'Black is beautiful' is to the Anti-Racism Movement (Abbas et al., 2004). 
Though Longmore grounds disability arts and culture within the political movement for rights and equality, he also argues that it is an essential part of the disability movement. Thus, the arts movement is both feeding and drawing upon the political struggle for rights and equality. Central to Longmore's analysis is that a collective disability identity must become something to celebrate. If this identity is not inherently positive, then why would people choose to label themselves disabled, and thus join the political struggle? However, the creation of a positive disability identity begs the question: positive to whom and under what terms? This has been problematic. The creation of a disability identity involves more than a simple matter of portraying disability in a positive way (Hevey 1993).

\section{IMPAIRMENT VERSUS DISABILITY}

Barnes et al. (1999) distinguish between artists with disabilities and disability artists. They note that there have been many artists in the past, such as Ray Charles, Hank Williams and Beethoven who have been recognized as artists with impairments. While this has added to the appeal of that particular artist, the influence of their impairment on their work has been minimized. Barnes et al. argue that impairment and disability are not considered as being part of the identity of these artists and they therefore should not be seen as being part of the Disability Arts and Culture Movement. 
The framework of disability arts presupposes the social model in understanding bodily impairment as being different from the social relationship of disability. This demands a new relationship between art and culture and Disabled Peoples.

Disability art is not simply about disabled people
obtaining access to the mainstream of artistic
consumption and production. Nor is it focused
primarily on the experience of living with an
impairment. Disability art is the development of
shared cultural meanings and the collective
expression of the experience of disability and
struggle. (pgs. 205-206)

In framing the disability arts movement within this type of political context, Barnes et al. argue that it is not and cannot only be about individual empowerment. It is about exposing structural relationships of power. They draw parallels between engaging within political action and engaging within the arts, arguing that both of these activities transform Disabled Peoples from being passive recipients to being active citizens. Instead of accepting an identity based on dominant frameworks of disability, Disabled Peoples are claiming and exploring their own identities. Disability arts is the process by which this exploration is occurring. To frame disability arts as being primarily educational is to limit its impact to individual empowerment and the acknowledgement of difference without addressing structural relationships of power.

Cheryl Marie Wade describes disability arts as "Identity Art that tells who we are, where we come from, where we're going, how we got here. Art that expresses the dreams and realities of a people. Of survivors." (quoted by Corbett,1996:174) 
This ties disability arts to the struggle for the Human Rights and equality of Disabled Peoples. Allen Sutherland argues:

I don't think Disability Arts would have been possible without disability politics. It's what makes a disability artist different from an artist with a disability. We do not see our disability as obstacles that we have to overcome before we try to make our way in a non-disabled cultural world. Our politics teach us that we are oppressed not inferior. We are 2 nd class citizens but not 2 nd rate people. We have the right to celebrate who we are and as we would not be who we are without being disabled, we have the right to celebrate being disabled. ... Our politics have ... taught us, not simply to value ourselves, but to value ourselves as disabled people. That's why we can have disability art; because we realize that our disabilities give us something to make art about. (From a speech to the London Disability Arts Forum Conference, July 24, 1989, quoted by Pointon \& Davies 1997:159)

\section{RELATIONSHIP TO THE MAINSTREAM ART WORLD}

Abbas et al. argue that one of the primary goals of disability arts is to change the character of mainstream art. They view greater exposure of disability artists within mainstream culture as supporting the struggle for disability equality. Similarly, Barnes and Mercer (2001) state that one of the fundamental goals of the disability arts movement is that the production and consumption of mainstream art be made accessible. 
While infusing a disability perspective into the mainstream culture is seen as being an important role for disability arts, there is considerable debate around how this should occur. David Hevey argues that the goal of disability arts is to "create cultural forms and agenda which bring the non-disabled world to us, not we to it" (1993:429). What is required of disability arts is what he terms as "political creativity." Hevey argues that the focus on attaining mainstream appeal has led to thinking about disability imagery primarily in terms of a positive/negative dichotomy. Both of these polar opposites are based on disability as impairment and social flaw. While negative imagery equates disability with a loss of control leading to either social or real death, positive imagery ends up "supporting the able-bodied management of these two fears." (p. 426) Thus, mainstream images of people overcoming their own impairments are held up as success stories for all, disabled and non-disabled alike. Yet, most Disabled Peoples do not overcome impairment once and for all. On this similar point, Irving Kenneth Zola (1983) writes:

The folk heroes of disability and chronic disease have been not the millions who came to terms with their problems but those few who were so successful that they passed: the polio victim who broke track records, the one-legged pitcher who played major league baseball, the great composer who was deaf, the famous singer who had a colostomy. They were all so successful that no one knew of their disability, and therein lay their glory ... Management in daily living does not involve dramatic tasks, but mundane ones. Examples of persons who overcame their disability once and for all mask the time element required for such achievements ... Moreover, the problem for the majority of the disabled is not a temporary one but one that will last a lifetime. (pgs 51-52) 
Hevey argues that disability artists need to "align their aesthetics and texts to a field which operates between their sense of self and their relationship to the movement, [and] changes to both will create the base of their continued aesthetic change and growth" (1993:429). Similarly, Paul Darke (2004) claims that work which attempts to represent disability through the mainstream arts, ends up "participating in the oppression of disabled people instead of challenging the very system that creates that oppression." (p. 15) Although Darke finds nothing wrong with artists who seek, or who have attained mainstream appeal, he also argues that they should be seen as being distinct from the disability arts movement. The mainstream is fundamentally obsessed with normality "That's the very thing that: constructs and perceives the abnormal to be second-best or not worthy at all." ( $p$. 16) The aim of disability arts is not only to question the social-political meanings of disability, but also to question the very art forms themselves, as well as who gets to do art, the standards upon which art is evaluated, and the professionalization of art.

Darke (1998) argues that disability imagery has been used to uphold cultural ideas surrounding normality. The role of the impaired character has been to represent "a perceived threat to the dominant social hegemony of normality." (p.184) The thrust of the story line is to create order and stability out of a presumed disorder and chaos represented by the disabled character's life. It is impossible for the character to integrate into society as they are. Thus, the focus is always on changing the disabled individual. "[T]he resolution for a normality 
drama's central abnormal character can vary in a range of specific narrative actualities (ranging from suicide to integrated normalization to an acceptance of segregation." (p.184) These types of narratives always follow the medical model of disability that concentrates on "impairment (abnormality) as an individual, pathological, problem to be either overcome or eradicated; the social elements of impairment (i.e. disability) are almost totally eradicated." (ibid)

Darke is critical of the push for more normalized images of impairment. $\mathrm{He}$ argues that "such images validate not difference but normality, the very illusion at the heart of the oppression of disabled people." (1998:183) Darke argues that we should view disability imagery in terms of the construction of the normal/abnormal dichotomy. Disability imagery should be seen in terms of the role that abnormality plays in culturally defining the normal. He argues that the use of impaired characters has been to "reinforce the illusions of normality: normality exhibited either in a film's non-impaired characters or by the impaired character's rejection of their impaired self." (p184) He further argues that the "discursive aim of the drama or narrative is constructed (either consciously or subconsciously) in order to reinforce and reaffirm the perceived social supremacy of normality." (p184)

The significance of this discussion to disability rights is that the experiences of Disabled Peoples cannot simply be added into a reality which has largely excluded disability and impairment from its construction. The inclusion of the 
experiences of disability which frame impairment as a valid part of identity challenges dominant constructions of reality. This places disability arts in a contentious position within the mainstream art world (Abbas et al. 2004). Art which disrupts dominant narratives and counters the status quo often carries the label of being political and therefore bad art. However, this more reflects the tendency to discredit the value of a particular work. Boal addresses this as stemming from the power struggle between oppressed peoples and the dominant classes over the ability to frame reality. The label of bad art should not be seen as necessarily reflecting on the quality of the work. Rather, this much more reflects the level of acceptance that the work receives from the dominant classes. However, an artist's access to resources, such as funding and training, are often strongly influenced by the dominant classes.

In saying this, I do not mean that we can not evaluate disability arts based on certain standards of artistic quality. However, we need to be critical of the standards by which art is evaluated. Hooks (1995), in discussing anti-racism and art, argues that an analysis of art based on power does not have to preclude an aesthetic analysis. Both types of analyses can occur simultaneously. Similarly, art that is created and produced from a critical awareness of power structures does not necessarily eclipse any attention being paid to aesthetics. Shape and form are as important as content. The label of bad art de-values the power of the work to redefine and reframe not only disability, but also the nature, form and content of art itself. 
Within performance, the new content being introduced by disability artists is breaking theatre conventions that dictate the use of space, movement, and voice (Wisehart 1997; Lewis 2000; Tolan 2000). This breaking of the rules, however, also makes use of established traditions within the theatre arts. At the crux, this breaking, making, and re-making of theatre conventions is about establishing points of power for Disabled Peoples on the stage. In analyzing my play, I will explore how the breaking and re-making of certain theatre conventions intervenes into dominant power structures around impairment and disability. 


\section{CHAPTER FOUR: METHODOLOGY}

The following methodology is based on the social model of disability which, along with a paradigm for theory, also provides a framework for researching disability issues (Barnes and Mercer 1997, Oliver 1997, Shakespeare 1997). Disability is theorized as a relationship between bodily impairment and the dominant set of structural arrangements. The significance of the social model is in its opposition to the individualized analysis of disability. Issues facing people with impairments are not viewed as individual pathology but rather as arising from structural relations which oppress people based on impairment. This creates a specific place from which I am conducting my own research. Rather than studying a group of individuals with specific functional characteristics, I am analysing the structure of power arrangements which oppress people and create disability as a specific category. As the researcher, then, I see my work as facilitating the political process of confronting oppression.

As a model of analysis, the social model is concerned with allowing the lived experiences of Disabled Peoples to have a primary role in researching disability oppression. To achieve this end, the methodology within this study uses qualitative research methods within an exploratory design to investigate my play. Before moving to a discussion of my methodology I will present a brief summary of the play Still Waiting for That Special Bus. This will help to contextualize my research design and methods. 


\section{SUMMARY OF STILL WAITING FOR THAT SPECIAL BUS}

The main character of the play is ALAN which is based on me as a (then) thirtyone year old single, white male with Cerebral Palsy. ALAN has attended university, has received his Bachelor's Degree and now has a job. He rents his own apartment. Due to his physical disability (use of a walker and wheelchair), ALAN relies on the local adapted transit system (Para Transpo) which requires him to pre-book his trips at least 24-hours in advance.

The opening scene is ALAN's living room. This is where almost the entire story takes place. The script describes the scene as "a mess, with clothes and books and garbage strewn everywhere. At center-stage is a worn easy-chair with a side-table. There is a phone on the side-table and a small radio among several books and papers. Alan's walker is parked center-stage-left with crumpled clothes hanging off of it." (Shain 2000:1) The plot or story line can be summarized in three stages.

For the first third of the play ALAN excitedly tells the audience about the date he has lined up for the evening (LINDA). We learn that they met each other a few nights before at a party and that ALAN took the initiative in asking her out. This is their first date together. ALAN also reveals that LINDA had some preconceptions about the date. She was surprised that he invited her out dancing, and that ALAN had chosen a club which has two flights of stairs at the entrance. 
In the second stage of the play ALAN grows increasingly frustrated over waiting for Para Transpo. When his bus is twenty minutes late he tries phoning Para Transpo, but is not told when they might arrive. The longer he waits for the bus, the more frustrated he gets. This frustration raises his self-doubt about the date. ALAN wonders if LINDA takes him seriously, or if the date is even worth all the effort it is taking him to get there. However, as he tells the audience about his plans for impressing LINDA and sweeping her off her feet, ALAN regains his excitement about the evening.

His renewed excitement soon disappears when his bus has become an hour late with no signs of showing up. ALAN angrily phones again to find out when they might arrive, but still gets no information. At a loss for what to do about his situation, ALAN briefly contemplates the taking of a cab. However, he estimates that this would cost him $\$ 40$ ( $\$ 80$ round-trip). ALAN rationalizes that this is too much money to spend on LINDA whom he hardly knows and has doubts about her interest in him.

The play ends with ALAN having given up on getting to the date. He is about to call it a night and go to bed when the phone rings. It's LINDA calling from the club where they were supposed to meet. She is wondering if he is still planning on coming. ALAN gets so excited that he runs out the door half dressed yelling for a taxi. His last line delivered to the audience is " $\$ 80-$ bucks! Here I come!" The ending implies that ALAN makes it to his date. 


\section{EXPLORATORY DESIGN}

Newman (1997) suggests that topics which are not well defined within the literature lend themselves more to an exploratory framework. This is to allow us to understand what is happening within a given situation before attempting to explain it (Shepherd, 2000). The purpose of this study is to uncover possible connections between theatre and confronting disability oppression. Thus I was exploring the ways in which my play highlights issues surrounding the politics of disability. My research design is therefore exploratory.

I connect Still Waiting for That Special Bus to popular theatre because it is based on and depicts my life experiences. However, I want to acknowledge that playwrights and directors create for many different reasons and their work operate on many different levels. Hence, in connecting my play to the disability arts movement, I am not suggesting that disability arts are only popular theatre. Rather, I am providing a case study of my play in order to provide a better understanding of the role of theatre in confronting disability oppression.

The focus of my analysis has been to examine the ways in which I have used theatre as an intervention into cultural understandings of disability. Rachell Gorman (2004), in problematizing theoretical approaches to disability oppression, treats four pieces of disability theatre as "conscious interventions, reveal[ing] aspects of our collective understanding of disability oppression, and our 
collective ideas about how to end disability oppression." (p. 88$)^{11}$ Gorman analyzes these works as forming part of the disability culture, and thus within the public domain, because each one of these pieces has been published or performed. Similarly, I am placing my play within the context of the disability arts movement, because it was developed as a dramatic work, and has been publicly performed in a variety of contexts and locations over the past 6-years. My play was intentionally developed to expose structural relations surrounding impairment and disability. Thus, for these reasons, my play can be approached as a dramatic work.

\section{QUALITATIVE ANALYSIS}

This thesis used a qualitative analysis of the content and structure of my play. "Qualitative research designs seek to understand human experiences from the perspective of those who experience them." (Yegidis and Weinbach, 1996:107) The researcher is situated within the research process, accounting for any particular biases which may affect the outcome of the study. "There is no pretence that the researcher can collect data in an objective, value-free manner." (ibid.) Oliver references Colin Barnes in stating that the researcher is either "on the side of the oppressors or the oppressed." (1997:17) In researching disability as oppression, I am siding with those who are oppressed by the dominant structure of power relations surrounding impairment.

\footnotetext{
${ }^{11}$ One of the texts Gorman uses in her analysis is from my play, which she summarizes as "reveal[ing] both institutionally structured relations (in this case, the ruling relations of [parallel transit systems] ) as well as the symbolic violence of 'common sense' ideas about disability." (p.139)
} 
Still Waiting for That Special Bus is described as a romantic comedy about the search for love and sex. The play description reads as follows:

[A] compelling semi-autobiographical story that is centred around a guy who simply wants to go out on a date. However, he has to wait for the Accessible Bus to pick him up. The longer Alan waits for his bus, the more he fantasizes - is she going to be the woman of his dreams, or is she going to be the woman of his worst nightmare? There is only one way to find this out, and that requires his bus to show up. (www.alanshain.com)

My analysis draws on themes arising from the literature review on disability arts and the politics of disability. The following four themes have been identified within the previous chapters:

i) the focus of mainstream arts and culture on explaining impairment;

ii) the overwhelming treatment of impairment by mainstream arts and culture as symbolizing weakness. Thus, Disabled Peoples are portrayed as being passive, powerless, evil, ugly, sick or defective, in the need of charity or a cure, or as triumphing over impossible odds;

iii) Disability Arts and Culture as being founded upon the social model of disability and carries forward struggle for the equality and Human Rights of Disabled Peoples;

iv) and the aims of the Disability Arts and Culture movement are to validate experiences of impairment while exposing and changing structural relations of power

My analysis is organized around the plot structure of the play, corresponding to the rising action, the climax and the resolution. In each section I discuss how 
both comedy and First Person Narrative are used as dramatic techniques to disrupt dominant narratives surrounding disability and impairment.

\section{RESEARCH MATERIALS}

My data materials will be the written script of my one-person play Still Waiting for That Special Bus [Appendix A]. The play underwent some minor changes after first performing it. Thus, the script I am using is dated from 2000 . It is a one-act play running approximately 45-minutes. I refer to it as being semi-. autobiographical because, while it is based on my experiences dating and socializing, the events in the play do not chronologically follow real life events. In other words, although the play takes place over the period of one evening, and revolves around one specific date, it does not represent one particular date over one particular evening within my own life. Rather, the story is based on an amalgamation of several different evenings and several different dating experiences which l've had. In addition, some events were embellished for comic and dramatic effect.

I will also make reference to a few reviews of the play to support my interpretation of the script.

\section{STRENGTHS AND LIMITATIONS OF THE RESEARCH DESIGN}

In choosing to study my own play rather than the works of other disability artists, I feel I have a deeper understanding about its content and structure because it is 
my own work. This has enabled a more detailed analysis of the dramatic choices which I have made in addressing disability oppression. With respect to disability, life-writing and autobiographical accounts have been useful in addressing the social construction of 'the disability-experience.' Kim Cordingly (2000) argues:

For people with disabilities, becoming the subject of one's own story enables the writer to construct a different subjectivity from the one often constructed within dominant social discourses. For women writers with disabilities in particular, life writing provides a way to embody a narrative and map a life that is often excluded based on a complicated axis of hidden geographies and subjectivities. (web document)

Although Cordingly's analysis supports the examination of life writing as a way to inform theory and practice, a point of clarification needs to be made: my play is being examined as a way to confront disability oppression, rather than how it maps out my life-story. Thus, while my primary data is my play, which is based on my own life-experiences, I am not intending to produce an experiential account of my life as a disabled person. Rather, I am using these experiences to explore ways in which social work can understand and confront disability oppression.

My approach follows closely to that of Tanya Titchkoksy (2003) who uses her own experiences with both dyslexia and her husband's blindness to examine cultural understandings of both disability and normalcy. This type of methodology uses the author's own experiences as a basis for social analysis. "The overriding decision upon which this book is based is to stay with the experience of disability as a significant social phenomenon that can reveal and illuminate culture. This 
orientation means that disability experience is a matter for social inquiry." (ibid:3) Thus, for Titchkoksy, her disability experience acts as a teacher in examining how we structure everyday interaction in terms of very specific ways of seeing and processing information. Her study was not an exercise in producing an account of her own experiences as a disabled person. This type of research creates theory and knowledge, rather than experiential accounts (Oliver 1997:9).

A limitation of this research design is that it is based on the experiences of a single individual. My own play solely deals with the experiences of a young, white male with speech and mobility impairments who is from a middle-class background. Thus, these experiences of disability oppression should not be taken to be universal for Disabled Peoples across different socio-economic and cultural backgrounds as well as across different types of impairments. The experience of impairment and disability is strongly influenced by class, race, gender, age, ethnicity and sexual orientation. Thus, my study should be taken as an entry point to the further study of the experience of disability and oppression. Generalized conclusions should not be drawn, as these experiences may not be representative of Disabled Peoples as a whole. 


\section{CHAPTER FIVE: ANALYSIS}

The comic premise of my play is that a disabled man (ALAN) has the date of his dreams (LINDA). He has set up to meet her at a local dance club. There is only one thing which could go wrong with his plans. ALAN is at the mercy of the accessible bus (Para Transpo) - and the bus might be late. Worse still, the bus might never even show up.

For most people, going out on a date is a regular activity. Yet, when impairment and disability enter the mix, dating becomes a monumental achievement. Lewis (2000) points to a long line of disability comedy troops, stand up comics, and performance artists who use humour to shed light on the political reality of disabled Americans. For example, she argues that the comic premise of "a quadriplegic buy[ing] some food and [trying] to eat it ... kick[ing] off a media frenzy" strips bare the social perception of Disabled Peoples as being incompetent (p.101). This use of humour counters the glorification of mundane activities such as self-feeding as being monumental achievements for Disabled Peoples.

The comedy within my play highlights the obstacles that ALAN faces to get to his date. By dividing the plot into three sections - corresponding to the rising action, the climax and the resolution - my analysis will explore the ways in which Still 
Waiting for That Special Bus employs comedy along with First Person Narrative to disrupt dominant narratives surrounding impairment and disability:

\section{RISING ACTION -> THE CHASE}

The dramatic structure of a comedy has been described as involving "the uphill struggle and eventual success of a sympathetic hero or heroine; [and] ordinary people in difficult but non-life-threatening predicaments." (Simpson 1998) I use this type of structure to frame ALAN as an ordinary person who has to deal with the extraordinary circumstances of parallel transit. The first third of the play focuses on how ALAN has met LINDA and what his hopes are for their first evening together. By developing ALAN's connection to LINDA, I set the stage for the uphill struggle of physically getting to the date. Thus the dramatic tension, or rising action, is caused by the increased tardiness of the Para Transpo bus.

In the opening scene ALAN is sitting in his living room chair beside the phone. $\mathrm{He}$ is staring out at the audience, and in mock disbelief he states:

Picture this. It's Friday night and once again I'm stuck waiting - waiting for that Special Bus. You see, I did my bit. ... I dragged myself out of bed early in the morning two whole days ago to book my bus. They better pick me up now, because l've got an incredibly hot date to get to! (Yells excitedly. Picks a shirt up off the floor. Twirls it around over his head and throws it.) (Appendix A:1) 
These first few lines are delivered with sarcasm, implying that waiting for the accessible bus is a regular impediment to ALAN's social life. Yet, he is also implying that he expects to be able to go out. After all, it is Friday night. The tone of sarcasm disrupts the perception of Disabled Peoples as passive individuals who accept the limitations they experience. ALAN is already questioning the level of service that he is receiving from Para Transpo by pointing out the effort it took to book his ride. He is not surprised that they going to be late, but he does not accept this situation.

By employing the literary technique of the First Person Narrative, ALAN is not only the protagonist or central character of the story, he is also the narrator. Thus, there is no mediating voice presenting ALAN to the audience. Particular strengths of the First-person Narrative is that "the reader usually gains keen insight into the life of the narrator ... [but] can also be used to withhold information from the reader, particularly information not available to the narrator." (Wikipedia 2005) Disabled characters are often in the margins of what is being told, remaining as shallow, uncomplicated figures. "From folktales and classical myths to modern and postmodern grotesques, the disabled body is almost always a freakish spectacle presented by the mediating narrative voice." (Thomson 1997:10; author's emphasis) Yet, as both the protagonist and narrator of this story, ALAN is in control. This story is not just happening to ALAN. He is telling about a new love in his life. He has specific plans for the evening - plans of his own making. 
The plot of the play is driven by ALAN's excitement and anticipation about making a good impression on LINDA. The audience sees the story from ALAN's point of view and gains intimate knowledge of his thoughts and feelings. He does not know what LINDA is thinking, and so, neither does the audience. By withholding this information, we share the intensity of ALAN's excitement and anticipation. This is done to establish a relationship with ALAN based on his desire for love and romance. One reviewer writes:

Shain guides us through the frantic strokes that all of us have taken in the image shattering current known as "getting ready". Shain could be any one of us: swelling with the expectation of romance, crushed with despair about his sex appeal, exploding with joy in anticipation of dancing cheek to cheek, doused with doubts about just how long his date will wait for him in the bar. (Rager 2002)

The audience thus becomes 'partners' in ALAN's experiences of waiting for the bus. My use of First Person Narrative gives ALAN power and control over the way this story gets told. Another reviewer writes "The effect is of being at home with a man who cannot use his legs, but moves about vigorously and unpredictably, and whose voice you have to carefully tune in to. As soon as you do you are you are confidante to Shain's humour, anxieties and social concerns" (Gallasch 2000).

\footnotetext{
ALAN's sense of vulnerability lies in wanting this first date to go perfectly. At the same time, I wanted to disrupt empathetic feelings towards ALAN based on a presumed weakness and vulnerability due to impairment. This was achieved by exaggerating his excitement.
} 
It's our first time going out together, so l've gotta do EVERYTHING I can to impress her, because this woman may be the one - the one who falls completely and madly in love with me. I've gotta put my best foot forward (looks down at knees) - or my best knee forward (sits with 1-knee out) so that she won't be able to resist coming home with me tonight!

(Arms out-stretched, singing off-key) THERE'S GONNA BE LOVE IN THE AIR, TONIGHT!

(Puts arms down, goes back to kneeling on both knees) O.K., maybe I won't sing. That might make her cry. I hate when people feel sorry for me. (Appendix $\mathrm{A}: 1)$

Exaggeration is a basic technique within comedy. Sandahl (1999), in directing Joan Schenkar's play Signs of Life, describes exaggerating her disabled characters' movements to the point of absurdity. She did this to also disrupt any empathetic feelings towards her characters that were based on impairment. Their movement choices were shown to be blatantly based on the existing power relations within the given scene, sometimes using the situation to their own personal advantage. I employed this same strategy in framing ALAN's desire for love, romance and sex.

(Starts talking excitedly) Once I had 3-women take me home - count them, 1, 2, 3 women! When they got me in my door, one of them asked if I needed any help to get into bed. (Pause, mimicking answering the question) Actually - now that you mention it - yes, I do need some help.

So they line-up my wheelchair beside my bed. Two of them grab one of my legs each. One grabs me under my arms and together the three of them lift and lay me gently on my back. One of them then asked if I needed help to get undressed. 
(Mimicking his answer to then, yells excitedly) YES!

(Finishes telling the story in a disappointed tone) She picked up my phone and started dialling her boyfriend saying he would be happy to give me a hand. And when he came over he did not have much sympathy towards me. (Appendix A:1-2)

What starts out as an extraordinary circumstance has a disappointing ending for ALAN. Yet because of his blatant attempt to use misperceptions of disability for sex we are not sorry for him. He has very self-gratifying goals. This was done to counter the use of impairment to symbolize innocence. In these first few moments of the play we learn that ALAN has sexual desires which he actively pursues. His hope that LINDA will be physically attracted to him is a normal desire for most people who are dating. Yet actively pursuing sexual desires is not seen as being normal for Disabled Peoples.

Morris (1991) argues that disability imagery is often used to signal an impediment to sexuality. She points to the biography of Christy Brown as depicted in the movie My Left Foot (1990). He is shown as being continually rejected by several women on the basis of impairment. When his attraction to his physiotherapist is again rejected, Christy responds by throwing a temper tantrum. Morris argues that this frames his sexual desires as being infantile and childish, and does little to change the dominant narratives around disability. Christy Brown is rendered powerless, his sexual desires remain unmet. 
Although ALAN also has sexual desires which are unmet, it was important not to frame him as powerless. In my play ALAN is an active subject; he is actively pursuing his sexual desires by taking the initiative to ask LINDA out on a date. My focus is on ALAN's struggle to get to his date, not on trying to persuade someone that he is attractive. Direct blame is placed upon the structures of public transit and of public space rather than on the character's particular impairments.

I wanted the audience to empathize with ALAN's desire for love and romance, but without framing him as weak (or virtuous for that matter) due to impairment. He alludes to the fact that he has experienced pain in the area of dating and relationships, which emerges as self-deprecating humour.

I think I give women the wrong first impressions. Women see how uncoordinated I am on my feet and think 'God knows the damage he would do in bed!'

Hopefully, my date tonight will find out that I am actually extremely gentle - aside from being a sensual hot-bed of sizzling sexual delights! (Yells excitedly while lifting up his shirt to show-off his chest to the audience) (Appendix A:2)

He has the ability to laugh at the pain he has experienced. The meeting of LINDA gives him new hope of finding love and romance.

This is the only time within the play that ALAN suggests he has issues with his body image. However, Tom Shakespeare, Kath Gillespie-Sells and Dominic Davies document how many people with impairments are very concerned with 
body image and the way that they appear to potential partners. They discuss three main issues related to dating $-i$ ) negative reactions from others about having a different body; ii) the lack of control which some impairments produce; and iii) the experience of partners' reactions to a different body. Most of the research that has been done on these issues, they point out, has involved disabled women. Thus, there is a lack of knowledge on how issues around body image may affect disabled men. However, disabled men have been the subject. of many popular films, such as in both Born on the Fourth of July and My Left Foot. Shakespeare et al. state "A typical theme in films about disabled people is of the man, often a war veteran, coming to terms with loss of masculinity through impairment - and this is usually characterized or crystallized in the context of impotency or sexual incapacity." (1996:62)

They further argue that there exists a stereotype that disabled men can overcompensate for their disability as a result of their masculinity. "Masculinity and femininity are in a process of transitional change within Western societies, which makes it difficult to generalize about the strategies of individual disabled men and women. The extent of denial, compensation, social acceptance, and the consequences in terms of role and identity are not clear cut ...Some women feel liberated from social expectation as a result of impairment; some men feel doubly inferior." (p.8) 
I wanted to contest these dominant portrayals of disabled men. The assumption of these films is that impairment is the antithesis to masculinity. Still Waiting for That Special Bus is not about ALAN struggling to be a 'real man'. I wanted to portray ALAN as being comfortable with his impairment and his sexuality. However, as I will discuss later on below, the play does explore his sense of masculinity in relation to his anticipated date with LINDA.

I framed LINDA as a virtual stranger to ALAN to address the assumption that special expertise is required to be with Disabled Peoples: She does not have any intimate knowledge of impairment or disability. Full participation according to Independent Living philosophy entails Disabled Peoples having the social freedom to meet and connect with others of their own choosing. The meeting of LINDA at a party implies that ALAN does have a certain amount of control over his social networks. His ability to meet people is not necessarily completely determined by structural arrangements based on his impairments. He has a certain amount of power in confronting social attitudes and in dealing with structural barriers. When ALAN first meets LINDA he suspects that she'll be just as patronizing as the other people at the party. He reveals that she had some preconceptions based on his impairments.

My date was a bit surprised when I said 'We're gonna go dancing tonight.' I guess she assumed we'd just be, you know, sitting around - watching a movie or drinking coffee somewhere. But she said she would love to go dancing with me, and that I am always impressing her with what I can do. (Pauses to chuckle) (Appendix A:2) 
Most audience members would probably relate to LINDA in this scene. They would share her surprise that ALAN invited her out dancing. Yet ALAN is the protagonist in this story, not LINDA. We therefore see this scene through ALAN's eyes. My use of comedy frames LINDA's attitudes toward his impairments as being absurd, and ALAN's desire to ask her out dancing as being ordinary. It is therefore not ALAN's responsibility to change her attitudes. Again, the use of First Person Narrative allows insight into ALAN's thoughts and emotions. He relates to the audience as if we share his sense of frustration. Yet, ALAN is not angry, he sees how this could work to his advantage. He recounts his conversation with LINDA at the party:

I hardly remember what we talked about. I just remember it was all about me. She kept saying "Wow! I'm so impressed!" - so naturally I kept on talking. ... I started telling her that I'm sick of my job. And she stops me in mid-sentence and exclaims, "You work?!" (Mimicking his answer to her) Well, I need to eat, and I like to drink, so I pretty much have to work. That kind of question usually pisses me right off. But she was cute. And I liked the way she laughed at herself afterwards for even asking such a question. (Appendix A:3)

LINDA is framed as being easily impressed, yet this is because of her lack of awareness of impairment and disability. She does not know what ALAN is capable of doing. But the play does not excuse LINDA for her lack of awareness. Instead, her impression of ALAN casts LINDA as being extremely gullible. ALAN takes advantage of the power he does have in this situation. This undercuts sympathy for the character based on an assumed weakness due to impairment. ALAN is in control of the situation. Yet, ALAN is not playing the role of teacher in 
educating LINDA. He is not a symbol of innocence by virtue of his impairment. He is attracted to LINDA. The comedy lies again in portraying ALAN as an ordinary person in unusual circumstances. Of course ALAN works! How absurd that LINDA would think otherwise! Of course ALAN is flattered that he is getting so much attention from an attractive woman. He is not used to this, and wants to play it for all it is worth. ALAN is admitting that most of his attraction to LINDA is on the physical level. Yet, we also learn that LINDA laughs at her own assumptions. This is important to ALAN and foreshadows an emotional connection to LINDA.

We learn that ALAN took the initiative in asking LINDA out on a date. By acting upon his sexual desires, ALAN is not passive and powerless. Yet, this scene also shows him taking a risk and making himself vulnerable to rejection. I wanted the audience to connect to ALAN's sense of vulnerability, as well as to his overwhelming desire to see LINDA again.

We ended up sharing a cab home together because we were both going the same way. All the way home I kept trying to figure out how to meet this woman again, because otherwise what was the whole point of meeting her in the first place? But nothing was working. ... As I got out of the cab | took a deep breath ... (Mimicking talking to Linda, nervous) I-I think we should go out. Wh-What's your phone\#? (Appendix A:3)

ALAN realizes that he does not have the immediate sex appeal that he once thought. LINDA was impressed with him at the party, but this does not translate into an automatic date. He has to do what any regular, ordinary person is faced 
with in this type of situation. He has to decide whether or not to make the first move and ask LINDA out. ALAN is forced to make himself be vulnerable to rejection. She does give him her phone number, but there is one problem neither of them have a pen and paper. ALAN memorizes LINDA's phone number and excitedly dashes into his building only to get stuck in the elevator on the way up to his apartment. When someone answers his cries for help, the only thing ALAN can do is to repeat LINDA's phone number and ask for a pen.

The confidence ALAN once had about LINDA has now eroded into desperation. Everything that could go wrong does - another typical strategy within comedy. ALAN is again framed as being vulnerable; he has lost control of the situation. Getting stuck in an elevator, not having a pen and paper handy are all things which happen to ordinary people. This undercuts the framing of ALAN as being a hero for asking LINDA out. ALAN boasts about how much he impressed LINDA by remembering her phone number the next morning (even though he did not remember her name) and how he used this to his advantage to get a date. LINDA is again portrayed as perhaps being a bit too easily impressed. This goes further to disrupt any sympathy for ALAN.

ALAN's pursuit of LINDA is at the expense of her own naivety. One reviewer questions this:

Intentionally or unintentionally, Shain comes across as a bit of a jerk, making fun of Linda for being lessthan-enlightened while commenting how much he'd love to have sex with her. (CT:2000) 
ALAN is undoubtedly in a position of power and control with LINDA as the object of his desire. The ways which I choose to confront assumptions that Disabled Peoples are innocent and devoid of sexual desire may be reinforcing power structures which have generally been oppressive for women. Although disabled men are not often portrayed as having power over others, images of women as subservient to male desire abound.

The reaction from this reviewer echoes similar comments that I have received, and perhaps stems from non-disabled theatre being stuck in the tragedy versus triumph paradigm of disability (Lewis 2000). This produces the expectation that the disabled character will either emerge as a hero or as a victim of their own circumstances. It is not particularly heroic or virtuous of ALAN to want to sleep with LINDA on the first date. Yet, ALAN thinks he has stumbled upon the power to instantly mesmerize her. The structure of a romantic comedy enabled framing ALAN as an ordinary character coping with unusual circumstances which he hopes will work to his advantage. Furthermore, as Shakespeare et al. aptly state, "It would be wrong to give the impression that disabled people were inevitably the victims of paternalism, infidelity, or sexual exploitation. Disabled people, just as non-disabled people, are capable of deception and less-than-perfect behaviour, especially men" (1996:121).

My overriding attempt was to disrupt the framing of ALAN as innocent based on impairment. Most reviewers identified with ALAN's desire for romance and his 
frustrations over trying to get to his date. They did not question the extent of his attraction to LINDA. For example, one reviewer called my play "An emotional slice of reality" writing "A simple plan, (to go out on a date) yes, but not so for someone with a physical disability." (Nathenson 1999) ${ }^{12}$

It is also the case that sexual relationships inevitably involve the dynamics of power and control; they carry a degree of objectification and fantasy which is not necessarily unhealthy or abusive (Shakespeare et al. 1996). Within the play ALAN is attempting to use his power to attract LINDA. Shakespeare et al. argue that "Disabled men do not automatically enjoy the power and privileges of nondisabled men" (p. 65). Thus, the power relationship between ALAN and LINDA is influenced by impairment. Her prejudiced attitudes are a factor in the ways in which ALAN is relating to LINDA.

I wanted to frame the waiting for the bus as the extraordinary circumstance, not the fact that ALAN has a date, in order to disrupt dominant narratives surrounding disability and sexuality. Shakespeare et al. write "The prevailing attitude, central to the prejudice faced by disabled people, is that disability and sexuality are incompatible" (1996:9). They argue that the assumption that disability is a medical tragedy underlies the barriers to sex and sexuality.

Stereotypes of disability often focus on asexuality, of lack of sexual potential or potency. Disabled people are subject to infantilization, especially disabled people who are perceived as being 'dependent'. Just

\footnotetext{
12 The Ottawa Sun led their review of the 1999 Ottawa Fringe Festival with the headline "Bus best ride at Fringe" and gave my play 5-stars. (Ian Nathenson, Ottawa Sun, June 25, 1999, p.34)
} 
as children are assumed to have no sexuality, so disabled people are similarly denied the capacity for sexual feeling. Where disabled people are seen as sexual, this is in terms of deviant sexuality, for example, inappropriate sexual display or masturbation. (p. 10)

Shakespeare et al. apply the social model to their discussion of the sexual politics of disability, arguing that the barriers experienced by most Disabled Peoples related to sexuality are the result of economic, social and physical discrimination, as well as cultural, attitudinal and psychological prejudice. This has led to Disabled Peoples being seen as either asexual or sexually deviant. Moreover, Disabled Peoples are typically framed as powerless in the area of sexuality. The root problem is that sexuality is not seen as a vital area of selfexpression for Disabled Peoples. "In modern Western society, sexual agency (that is, potential or actual independent sexual activity) is considered the essential element of full adult personhood ... because disabled people are infantilized, and denied the status of active subjects, so consequently their sexuality is undermined." (p9-10)

Works, such as Francois Archambault's play $15-$ Seconds $(2000),{ }^{13}$ follows these dominant narratives of disability, sexuality and powerlessness. The story revolves around two brothers, Mathieu and Claude, who are both in love with

\footnotetext{
${ }^{13}$ I pay particular attention to this work because it gained such high notarity and praise for being honest and truthful. First produced as part of the 1997 Juste Pour Rire Festival , "it subsequently won the Governor General's Award; presented, in English - translated by Bobby Theodore - by, among others, Great Canadian Theatre Company, Belfry Theatre and Alberta Theatre Projects all during the 1999/2000 season)." (quoted from http://www.canadiantheatre.com/dict.pl?term $=$ Archambault $\% 2 \mathrm{C} \% 20$ Francois)
} 
Charlotte. The whole focus of the play is on Mathieu's struggle to persuade Charlotte to accept his impairments, and this is framed as the key to establishing an intimate relationship. Despite his desperation, however, Charlotte does not fall in love with Mathieu. His abysmal failure in the end is represented as Mathieu's only chance at love. Since Mathieu cannot change the fact that he is impaired, his efforts are seen as being doomed from the very start.

Stories such as 15 -seconds ignore the structural barriers to Disabled Peoples' sexuality. While many Disabled Peoples find it difficult to pursue meaningful sexual relationships, it is often due to isolation and discrimination. Charlotte's attitudes are never questioned throughout the play. It is taken as a given that she is not attracted to Mathieu because of his impairments. There is no room left for the possibility that someone else might find Mathieu attractive, or that Mathieu and Charlotte are not compatible, or a whole range of other possibilities as to why two people don't end up falling in love.

Within Still Waiting for That Special Bus ALAN chooses not to give LINDA a medical explanation of his impairment. She also does not ask for such an explanation. In framing LINDA as not being concerned with the medical causes of his impairment, I am reflecting my own experiences. Within my sexual relationships involving non-disabled people, my partners have never been overly concerned with my medical history. In fact, I don't ever remember any of them wanting to know about the medical causes of my Cerebral Palsy. In one instance, however, a partner of mine had been pressured by her parents for this medical 
information. They were shocked to find out that she did not know and that I had not talked about it. We were in the third month of our relationship. This illustrates the importance not to assume that non-disabled partners would necessarily require a medical explanation of impairment. Thus, I framed LINDA to challenge the idea that impairment is always a primary concern for an able-bodied partner. Rather, the most important concern for both parties of this budding relationship is the inaccessible transit which keeps LINDA and ALAN apart.

Much of the research and information on sex and disability is concerned with sexual functioning (Shakespeare et al. 1996; Deloach 1994). Once again, this reflects a focus on the medical aspects of impairment to the neglect of the social constructions of disability. As I will discuss throughout this chapter, most Disabled Peoples are primarily concerned with the structural and attitudinal barriers to initiating and maintaining intimate relationships. "An abundance of anecdotal reports and research findings reveal that there exists a widespread belief that individuals with disabilities are asexual - that they lack sexual desire, the ability to partake in sexual activities, and the capacity to engage in long-term, mutually satisfying, sexual relationships." (DeLoach 1994:20) It is these perceptions, rather than the impairment itself, which pose the greatest barriers for Disabled Peoples.

The focus on impairment and sexual functioning has created the pressure to disclose impairment for many Disabled Peoples. Often individuals fear rejection 
when considering whether or not to disclose impairment. However, not disclosing the medical causes of impairment can be seen as being deceitful. I would argue that this again reflects the misperception that the medical causes of impairment are a primary factor within relationships involving Disabled Peoples.

Nonetheless, the issue of self disclosure - when and how to disclose impairment - is a central concern for many Disabled Peoples, particularly if the impairment is invisible (Shakespeare et al. 1996; DeLoach 1994; Breckwoldt 1989). However, even when it is apparent how the impairment affects the individual, a choice still has to be made over the timing and nature of disclosure.

The fact that ALAN has met someone who is interested in him confronts the prejudice that disability and sexuality are incompatible. While I do not want to deny the difficulties that are experienced in meeting people and forming social relationships, I also do not want frame Disabled Peoples as being completely isolated by the barriers that they face. Thus, although the play implies that waiting for the bus is a regular impediment to ALAN's social life, it is also implying that he regularly goes out on a Friday night. This was done to reflect my personal experience of often encountering the surprise that I do have an active social life. While in college, a career counsellor assumed I would be more focused on my studies because my bus picked me up at a set time everyday! She thus did not understand that, as many young people experience upon 
graduating from high school, I would be struggling with issues of balancing academics with new-found social freedoms.

CLIMAX $\rightarrow$ WAITING, WAITING AND WAITING ...

Romantic comedies typically involve "a love affair that meets with various obstacles (like disapproving parents, mistaken identities, deceptions, or other sorts of misunderstandings)." (Bedford St. Martin's, web document). By framing ALAN's pursuit of love and romance in terms of a romantic comedy, his attraction to LINDA is presented as being quite normal. It is the accessible bus which plays the role of disapproving parents, regulating when ALAN can go out, for how long and when he has to be back home. ${ }^{14}$

Irving Kenneth Zola, one of the first to write about Independent Living as a paradigm for understanding and researching disability, writes "The Independent Living Movement argues that it is more important for us have full control over our lives than over our bodies." (1983:58) What ALAN wants is control over his life. Yet this does not entail overcoming his impairments. Within the play, ALAN's impairments are not a source of anger and frustration. Yet, the structural relationships which ALAN must enter into on a daily basis are portrayed as impeding his life. These are portrayed as barriers to his full participation generating anger and frustration.

\footnotetext{
14 Thankyou to a discussion with disability scholar Dr. Nancy Hansen who provided this interpretation.
} 
Although ALAN does express doubts about whether or not LINDA is interested in him, this is framed as being a normal part of going out with someone new. It is only within the context of waiting for the bus, and later on, contemplating the taking of a cab, that ALAN begins to have self-doubts. Is she worth all this trouble and effort? He does not know what her intentions are for the date. He has only met her once before. How deeply is LINDA attracted to ALAN? These are reasonable questions to have for a first date. Yet, the structure of the accessible bus service increases ALAN's sense of risk to absurd levels. He had to get out of bed at 7 am the day before to book his ride. When the bus verges on being an hour late, he is forced to contemplate spending $\$ 80$ on a cab to get to the date (\$40 each way). This is an incredible amount of effort to meet someone ALAN hardly even knows. It is all this time and energy ALAN is forced to expend that is absurd, not his desire to meet LINDA.

The subject matter of comedies is not necessarily always light, but may reveal harsh truths or threatening situations (Simpson 1998). Treating this story as a comedy reveals the absurdity of the structural limitations that are being placed on the lives of Disabled Peoples. It is absurd that the adapted transit system controls and curtails ALAN's chances at love and romance (and of course at getting sex). Yet, this also reveals a harsh truth. Dependency on a parallel doorto-door service is a political reality for most disabled Canadians. This is due to a combination of factors including climate, distance to the regular bus-stop, safety 
issues, and a lack of public buses that are, in fact, wheelchair-accessible. For example, within Ottawa $52 \%$ of the fleet are accessible. ${ }^{15}$ This means that a person risks getting part way to their destination, only to find out that they must transfer on to an inaccessible bus. There are no Canadian cities with a fully accessible public transit system. Vancouver, British Columbia is recognized as one of the first to start converting its public buses in the late 1980s (Greater Vancouver Transit Association 2005). It has only been since the late 1990s that a handful of other cities have started putting accessible buses on the road. The downloading of services from the federal government to the provinces in 1997 placed Ontario's public transit under the jurisdiction of municipalities. This has resulted in a significant drop in funding awarded to local transit authorities. Although municipalities have recognized that it is cheaper to provide accessible public transit than a door-to-door service, their limited access to resources places the retrofitting of buses and local trains on an extremely long time-line.

Accessible transportation is one of the cornerstone issues for the Independent Living Movement. Transportation is the means to full citizenship. "Without means of transportation to educational, vocational, cultural, recreational, and commercial facilities in the community, it is impossible for most severely disabled people to live outside an institutional setting. Thus, in a very real sense, transportation is a key to independent living." (Bowe 1983:205) Although Frank Bowe wrote this almost 25-years ago, as the above discussion demonstrates, adequate authority (OC Transpo) on March 16, 2005. 
transportation still remains a fundamental barrier to full participation for most disabled Canadians.

Dependency on a door-to-door service contributes to the social isolation experienced by a lot of disabled peoples. Most parallel transit systems are overloaded with demand. Within Ottawa, Para Transpo reported having to deny 46-thousand trips in 2000 (OC Transpo 2001:5). While for many Disabled Peoples the cost of a cab is prohibitive, for many others taking a taxi has also been physically prohibitive. Until very recently Ottawa only had one accessible cab which was often not on the road. Thus, there were no cabs which could accommodate people who use wheelchairs. The purchasing of one's own wheelchair adapted van is also extremely cost prohibitive. ${ }^{16}$ This means that Disabled Peoples are often left without any access to transportation.

Within my play, access to transportation symbolizes ALAN's key to his date for the evening. If the bus does not show up, ALAN's dreams of romance with LINDA will disintegrate into thin air. The main source of dramatic tension, thus, revolves around the lack of adequate transit. ALAN has found someone who is interested in him, but without transportation this date is rendered meaningless.

The play highlights the ways in which the character is made entirely dependent on an inadequate transit service. It reflects my personal experiences of being isolated, but not as a result of my lack of social skills in meeting people. I would

16 In my own research to buy a wheelchair accessible van, I discovered that a new van cost 80-thousand dollars, while a used van cost 50-thousand dollars. 
often be faced with the choice of staying home or spending a large portion of my budget on taxi cabs in order to go out. Shakespeare et al. argue that structural barriers often create personal issues for Disabled Peoples in their sexual development. The focus of their study was to show these personal barriers as being the effects of segregation. Thus, in my play I frame ALAN's self-doubt as stemming largely from the lack of adequate transit. The amount of effort that it is taking him to get to the date heightens his doubts about LINDA. Yet, this also creates a sense of desperation for ALAN. Underlying his excitement and anticipation about this particular date is the loneliness he faces. However, these personal issues of loneliness and desperation are not framed as character flaws. They are framed as being the result of structural and attitudinal barriers. $\mathrm{He}$ briefly mentions a date in the past who took pity on him. He alludes to the fact people often have poor first impressions of him that are difficult to change. LINDA could be different. She might have a good first impression of him, but ALAN does not really know. He is frustrated by all the effort it takes to find out what LINDA thinks about him. This is a process which most people go through upon meeting someone new. However, it is complicated by the structural oppression which results in many Disabled Peoples feeling that dating and sexual relationships are off limits for them (Breckwoldt 1989; Yolinda 1994). While this could be interpreted as the result of low self-esteem, I would argue it is a case of internalized oppression. 
For example, the first time ALAN expresses self-doubt about the date, he angrily tells the audience:

I know what will happen tonight! I'll get there, and then she'll insist on buying all the drinks. I invited her out and she won't let me pay for anything. That's how l'll know! That's how l'll know that Linda doesn't think of this as being a real date! (Appendix A:6)

This anger is misplaced. It is not really about LINDA as much as it is about ALAN constantly feeling that he is an object of pity. Karen K. Yoshida (1994), in her study of men with acquired impairments highlights the difficulty they have in meeting women who find them attractive. These men feel that they are not being viewed as a potential sexual partner because of their impairment. Shakespeare et al. argue that many disabled men experience this as being a denial of their masculinity:

Sometimes, young disabled men, because they are seen as unthreatening and asexual, may have closer relationships with women than their other hetrosexual peers, perhaps replicating the relationship between gay men and straight women. However, in the case of disabled hetrosexual men, this enhanced communication with the opposite sex also involves denial of their sexual potential, and can be undermining. (1996:63)

ALAN can also be seen as experiencing a denial of his masculinity. An example of this is his frustration that LINDA is impressed that he has a job and over his ability to go out dancing. He feels that she is framing him as passive and dependent because of his impairments. ALAN expresses anger at the way she labels him as being special. He also discusses how important it is that LINDA does not walk him to his front door on the way home from the party and she lets 
him pay for the cab. These responses come largely from ALAN's experiences of being an object of pity. But it also comes from his desire to be seen as a potential sexual partner.

When we shared that cab home the other night, and I was fumbling for my wallet to pay for my share of the cab, she let me pay. And then she jumped back into the cab and took off. She didn't wanna walk me across my own street, make sure I was 'safe.' That gave me a good feeling about her.

(Pause. Laughs) Listen to me talking! I'm making WAY too much out of Linda. I'm falling for some one who let me pay for my own cab! Alan, get a grip! (Appendix A:6)

In this instance, the character senses that LINDA is not trying to take care of him. He sees this as an opportunity to be taken seriously by LINDA. He then catches himself for reading so much into that one interaction. Yet, first impressions are typically based on one small thing that was said or done. ALAN uses what could be seen as a minor detail to judge the possibilities of a potential relationship with LINDA. He does not really know whether or not she'll be patronizing. He does not know if he has read her in the right way. By speaking this interaction with the cab out loud, ALAN realizes how little he has to go on about LINDA. Yet he is putting all this energy into going out with her. Why? Because she let him pay for his cab. He begins to think himself as being silly for getting so worked up over LINDA. It also points to ALAN's vulnerability in his desperate attempts to connect with someone. Despite the warning signs that she might be a dismal failure (calling him special, being surprised that he has a job) he is still willing to take this risk 
based on that she let him pay for his cab. This highlights ALAN's sense of isolation. He does not see many other opportunities to connect with someone.

Sandahl (1999) argues that performance needs to show the connections between impairment and disability in order to both deconstruct and reconstruct disability identity. Similarly, Hevey (1993) argues that disability artists must portray our political struggle for both personal and collective identity. He discusses the need to "create a political poetic of the self and the group. We will be able to define our impairments away from [character] flaws by making culture and art which shows the process of our transformation." (pgs 427-428)

Impairment and disability are framed as both affecting ALAN's life, yet in different ways. His mobility and speech impairments are portrayed as simply being part of ALAN's life. He arranges his apartment accordingly. The set shows how ALAN positions things like tables, chairs, books and papers in terms of the way ALAN moves through space. ALAN does not explain why his books are on the floor. Everyone expects his books to be on the table, but they have to accept that ALAN's books are on the floor because that's where ALAN puts his books.

The audience is also immediately confronted with the fact that ALAN moves around on his knees. The prominence of ALAN's walker - that it is readily available to him - underscores ALAN's choice to crawl. It is not out of necessity. The clothes piled on top of the walker suggest that he regularly crawls. Thus, ALAN's physicality is not shown in terms of a burden or something to overcome. 
It never seems awkward, throughout the play that ALAN moves around on his knees. He also never attempts to explain or justify the way he moves. The audience is forced to accept this as the normal state of affairs. Again, I chose not to give in to the typical question, 'Why is ALAN like that?' This wasn't what I wanted the play to be about.

ALAN's private space is directly contradicted by an inaccessible and inhospitable public environment. The only point where ALAN uses his walker is when he describes what he has planned for the date. We are transported into a public space. We are no longer in his living room but at the actual club where ALAN is to meet LINDA. The use of his walker highlights ALAN's need to adapt to public space. His body has to act in normative ways in order to be accepted. Yet, this is framed as absurd instead of being an act of triumph. The stairs are portrayed as an obstacle to ALAN's normal desire to go out dancing.

This also highlights the extent ALAN is going to connect to LINDA. He feels that he has to adapt as much as he can to fit into the structures around dating and socializing. Instead of adapting the date itself - where they meet, what they do ALAN adapts his body to an inaccessible place in order to make this date happen.

The walker symbolizes the adaptation which many people with mobility impairments must make to public spaces. The physical effort inevitably taken by 
this process often becomes a deterrent to socializing. Within my personal life, I am continually weighing my desire to go out against the amount of energy that it takes me to manoeuvre within public spaces. I often cannot bring my main mobility device, which has been a motorized scooter or wheelchair, when attending a private party or a night club. I've frequently chosen not to go out because of the physical effort it takes to walk.

At several instances throughout the play ALAN contemplates taking a cab instead of waiting for the bus. Each time, however, he decides it would be too costly to take a cab. Yet, the pre-booking of the Para Transpo bus also complicates his plans. He tells the audience:

It was so awkward asking Linda where and when we were gonna meet 3 whole days before the actual date. She wanted to wait and set all that up this afternoon, saying that she was more of a spontaneous type. But that kind of spontaneity would cost me about 40-dollars in cab-rides - and I only have 40-dollars I can really spend tonight. I mean, I want at least some money I can spend on the actual date. (Appendix A:6)

ALAN feels it is important to have money to pay for drinks on the date. He thus decides that booking a bus is the lesser of two evils. Most adapted transit systems require one or two days advance booking. This demands an incredible amount of planning on the part of users. It is extremely difficult to change a booking once it has been made. This situation imposes a fairly rigid structure on people's lives. Across Canada, advance booking can range anywhere from 4hours to more than 1-week before the desired date and time. 
While it is common for most people to want to be able to treat their dates, Disabled Peoples are often not expected to be taking care of others. Shakespeare et al. document many Disabled Peoples being frustrated by the assumption that their sexual partners are their caregivers. For example, one male respondent finds that restaurant waiters frequently give the bill to his ablebodied partner (p.65). This reflects the prejudice that Disabled Peoples need to be cared for.

The climax of the play occurs when ALAN phones for the second time to find out about the bus. He has been waiting for over an hour. They tell him that the original bus is not going to show up, but that they'll be sending out another vehicle. Although the story validates ALAN's anger, he cannot get any information as to when the second bus will arrive. I structured the plot in this way to reinforce the lack of control ALAN has over the transit situation. He has been waiting patiently over the past hour but is left with little chance of getting to the date that he has been anticipating for the past three days. This illustrates the passive relationship that passengers are expected to have with the parallel transit system.

It is a turning point in the play because ALAN now seriously doubts he'll make it to the club. The frustration over not having adequate transit results in ALAN 
giving up on LINDA. He contemplates the taking of a cab, but decides the risk is too great.

(Stares out at audience, bewildered) What am I supposed to do now? (thinks, begins to re-gain composure, hopeful) Hey! I should take a cab! I mean, so what if I spend 40-bucks on cabs and another $\$ 40$ on Linda! At least I would have gone! I would have met Linda, and I would have found out what she really thinks about me. Right?

(Thinks, starts getting downcast) As if I really need to go to find that out. (Starts taking off shoes, talking to himself, consoling) C'mon Al. You're 32-years-old! Too old to be still going out, chasing women who you don't even know. If you haven't met that special some one by now, then you probably won't. Face it Alan, you're alone, there's nothing wrong with that, is there? (Finishes taking shoes off) (Appendix A:8)

Throughout the play ALAN has been continually questioning whether LINDA sees him as a potential partner. He rationalizes that he does not know her very well and that the date would probably not be worth the cost of a cab ride. He views his age as an additional barrier to going out with LINDA. He feels he does not meet up with the expectation that people in their thirties should be settling down and starting a family. ALAN struggles with feeling that there is something wrong with him because he is not at that stage in his life, even though he is thirtytwo. As I will discuss more fully within the next section, the play shows ALAN's outright anger at confronting these stereotypes of being disabled, being someone in his thirties, and being single.

RESOLUTION -> SHE LOVES ME ... SHE LOVES ME NOT 
Sandahl (2002) argues that the dramatic representation of disability, whether it is positive or negative, almost always ignores the material conditions of the disabled character. Likewise, Lewis (2000) observes that disability has traditionally been represented as a static state of being. In reality, the experience of disability changes according to material circumstances (Oliver 1996). The fact that ALAN is employed and earning an income does give him certain power to define his reality. His sense of isolation would likely increase dramatically if he did not have access to the resources to meet his housing needs and enjoy an active social life. Yet having a job does not solve all of ALAN's issues. Earning an income does not buy ALAN a date with LINDA. She does not fall in love with ALAN because he has a job. Likewise, the Para Transpo bus does not come any faster because ALAN is employed. According to the Independent Living model, full citizenship for Disabled Peoples requires structural changes, as opposed to individuals fitting themselves into current structures. ALAN still has to confront general perceptions that cast him as unemployable, and therefore one of the worthy poor, At times, ALAN successfully confronts these perceptions, as in his first conversation with LINDA. At other times, however, ALAN is unable to navigate social perceptions which isolate him as a disabled person.

The lack of transit is represented as the underlying factor for ALAN's sense of loneliness and isolation. Yet, he complains that his friends assume he is single due to his impairments.

(Angry) I went to this wedding - it was about a month ago. It was with a bunch of old school friends from 
University. And they were all married or living with some one - some even had kids. And then there was me. No one ever gave me the chance to explain myself - that I just haven't met that 'special some one' yet ... And maybe I would meet some one if I could ever get out of the house ... None of them ever thought about that whenever I wanna go out - to do anything at all - I have to book one of these special buses! I feel like such a baby - having to phone them up 'Hi, can I please go out tomorrow?' (Calming down) It's as if we disabled people need permission to be out in public! As if we're not supposed to go out to parties - and have fun and actually meet people! (Appendix A:8)

The lack of expectations from parents, friends and family that Disabled Peoples would either be involved or interested in sexual relationships is reflected in the literature. Shakespeare et al. argue that this is another way in which their sexuality is denied, and often leads to experiences of isolation. ALAN feels that his friends have always assumed that he would not be with someone because of his impairments. He is portraying them as not understanding the intricacies of his life. The tone of the play has changed from comedy to outright anger. ALAN feels his friends are unable to see how he is isolated by the structure of public transit. He also feels that he no longer fits into the social structures of his old school friends. Their lives are now based on raising a family or on living with their partners. He feels isolated from their experiences.

There is also a strong cultural resistance to seeing Disabled Peoples as parents. Shakespeare et al. speculate that this stems from a number of prevailing attitudes - i) the eternal innocence placed on Disabled Peoples; ii) the fear that Disabled Peoples will breed more Disabled Peoples which will then be an 
increasing burden on society; and iii) becoming parents places Disabled Peoples into positions of authority and power which are thought to be reserved for nondisabled people (p. 108). For many people, it is assumed that a life-long sexual relationship will produce children. The resistance to viewing Disabled Peoples as potential parents further undermines their sexuality. The prejudice ALAN faces compounds his anger at the passive relationship that he is forced into by having to rely on Para Transpo. This is made very poignant in the line about needing permission to be out in public.

Shakespeare et al. document the inaccessibility of nightclubs and parties for many Disabled People. They comment that some barriers are due to physical lay-out, while others are due to the nature of an individual's impairment. For example, one respondent who is blind discusses the issue of a lack of eye contact in either initiating or responding to someone's advances. "I cannot respond ... visually to body language. I am often thought to be rude, drunk or not interested." (p. 31) Another respondent says:

At parties sometimes, it's not been unknown for me to just sit there for about half an hour or even longer before I get talking to someone, and that's not a lack of confidence on my part, it's the fact that there could be dozens, if not hundreds of people in any one room, and to start wandering around you are going to bang into people, you are going to knock things over, etc." (1996:32)

Shakespeare et al. note that most of these barriers "can be alleviated, circumvented or removed with appropriate provision and behaviour on the part of society. Unfortunately, the experience of our respondents is that this is often not 
forthcoming" (p. 33). They reference Vic Finkelstein in stressing once more that "[p]sychological insecurity and distress are a result, therefore, of the social relations to disability, not the physical experience of impairment (Finkelstein, 1993)." (p. 42)

For ALAN this lack of mobility due to impairment adds to his stress of attempting to circumvent attitudinal barriers. The next scene illustrates the way in which social perceptions along with physical and structural barriers compound the restrictions Disabled Peoples often face in attempting to initiate relationships. He speaks angrily about others at the same party where he met LINDA.

And then I get to one of those parties like the one on the week-end. I get myself there and then no one talks to me. It was up to me to push my walker between people and try to blend into whatever they may be talking about. And when I did, their conversation would stop dead! All anyone ever said to me was, 'Do you want another beer?' (Appendix A:8)

ALAN's experience of exclusion is multi-layered. He makes reference to the physical effort it takes to manoeuvre in and around, and between people due to impairment. Yet, he also feels it is his responsibility to include himself in the party. However, ALAN's efforts are met with patronizing attitudes which continue to exclude him. They do not engage him in conversation. People only want to take care of ALAN, to make sure he is comfortable.

The attitudinal barriers ALAN is facing in the above scene stem from viewing people with impairments as objects of pity. Framing Disabled Peoples to promote 
"public pity has been consistently used as an effective fund-raiser for human service organizations serving people with disabilities. Posters, billboards, and telethons depict brave but pitiable people." (Makelprang 1998:5) This approach to framing disability has been widely politicized as continuing the oppression of Disabled Peoples. Ronald Makelprang argues that "the result is that human service professionals involved in these kinds of fund-raising events inadvertently reinforce negative stereotypes." (ibid) The overriding theme of charitable images of disability is that Disabled Peoples are sick and that charities must raise money to heal them (Haller, 1993). This portrays Disabled Peoples as passive objects of charity, being entirely dependent upon the goodwill of others. As I have argued elsewhere, the ways in which I frame the character of ALAN challenges this perception of Disabled Peoples. Yet, I also wanted to show how this widespread use of disability imagery directly impacts ALAN's life and his pursuit of sexual relationships. Rather than assisting him, these images of Disabled Peoples as objects of pity act as barriers to ALAN's full participation. LINDA is surprised that ALAN works. At the party people only want to take care of ALAN without engaging him in any meaningful conversation.

The story is now back at the scene towards the beginning of the play - when ALAN first met LINDA. But we see it from a different perspective. Instead of a humorous tone, we see the scene through ALAN's sense of frustration. ALAN is angry at everyone at the party, and this includes LINDA. Initially he dreads having to talk to her. He thinks he is going to have to deal with the same 
patronizing attitudes from her as from everyone else. ALAN then describes the initial attraction that he felt towards her.

That's when Linda sat down beside me, and I remember thinking 'Oh shit, not another one!' But the moment we started talking I could tell - right away we connected. (Pause) It was her eyes. When she was looking at me, it felt like she was really looking at me. You should have seen her at the party. She was so beautiful. (Appendix A:9)

The way that she initially looks at him is the most important thing for ALAN. It is in sharp contrast to the way others have been looking at him throughout the evening. He has been feeling like an object of pity, yet he feels that LINDA does not objectify him in this way. She looks at him in a way that seems affirming, seems inviting. He feels personified, rather than objectified.

This is the first time ALAN specifically talks about what physically attracts him to LINDA and we learn that it's the way that she looks at him. He is physically attracted to her eyes. ALAN does not expand on this because he feels that there is not much more to expand upon. He simply likes the way that she looks at him. Sexual attraction often begins with a look or a glance. The play is drawing on that experience of a first attraction to someone, how simple it can be and yet how moving it can also be. However, ALAN minimizes his attraction to LINDA to deal with not being able to physically get to the date.

And now I have a date with her and I can't even get there! (Pause, calmer) Well, I could get there if I was willing to call a cab and end up spending 80-bucks tonight. 
(Pause) But I cannot go around spending all that money every time I just happen to like some woman's eyes! (Starts taking his shirt off) I'm going to just get undressed, go to bed, and forget all about Linda. Forget all about our date tonight. (Appendix A:9)

ALAN briefly talks about a past relationship in musing what LINDA 'could' have been, or 'might' have been.

It would have been nice if Linda did turn out to be some one special. I remember my last girlfriend Carol. She could always make me laugh. Even when it felt like my whole world was falling apart, she could make me laugh it off. Just create a new world, she'd say, and we almost did create our own little world. We would spend hours just lying with each other. Her hands forever touching my naked body. And she'd whisper into my ear, "Alan, you're perfect - and you're all mine!"

(Laughs) That gave me such a surge of energy. (runs across down-stage, on knees - arms out-stretched showing off his bare chest) I felt like running out into the world naked and saying "Hey everyone! Look! Look at me! I'm perfect!" (Appendix A:9)

A major aim within the play was to challenge the portrayal of Disabled Peoples as being either asexual, or sexually inexperienced. Shakespeare et al. write that "Although we have explored difficulties with making and maintaining relationships ... we do not want to reinforce the idea of disabled people as victims ... Therefore it is important to state that, issues of power and discrimination notwithstanding, our research shows that positive and fulfilled sexual lives are a reality for increasing numbers of disabled people." (p. 96) Therefore I did not want to present ALAN as a complete victim of barriers and discrimination. He has had past sexual relationships. LINDA is not his only hope. I wanted to show that 
ALAN does have somewhat of a fulfilled sexual life, but I also wanted to balance with the barriers and discrimination that ALAN faces. As such, I felt it was important that LINDA wasn't framed as being ALAN's first love. This would have established a more static relationship between ALAN and oppressive power structures. Though he continually struggles against isolation, ALAN's life has not been completely pre-determined by these types of barriers.

As well, casting LINDA as his first love would have made ALAN seem more innocent in his chase and 'lusting' after her. The fact that he has had past relationships gives his pursuit of LINDA more depth. It allows for a more mature understanding of intimacy as well as the possibility that ALAN is looking for this in a relationship from LINDA.

Towards the end of the play, ALAN states:

I wonder how long Linda will wait for me. (Chuckles) As if she's even there. She probably didn't believe we were really going to be dancing tonight. When I told her to meet me at the Mercury Lounge, she said "How are you gonna get in? There are two flights of stairs going up!"

I told her I get in like everyone else (starts crawling) up those stairs one by one - except l'm doing it on my hands and knees. There's so many stairs in Ottawa that, if some one wants to go out, listen to some music, drink some beer, they pretty well have to go up or down stairs. I told Linda that, as a result, I spend a lot of time on my hands and knees - especially if it involves dancing with a beautiful woman. (Appendix $A: 9-10)$ 
In the above scene, he mimics crawling up the stairs. The crawling is awkward and forced to represent the physical effort it takes ALAN to enter the club. This scene -represents the extent to which ALAN will, and is forced to adapt his body to the social environment. The stairs do not stop ALAN from entering the club, but only if he is willing to put in the physical effort it takes to climb them.

This also highlights the extent ALAN is going to connect to LINDA. He feels that he has to adapt as much as he can to fit into the structures around dating and socializing. Instead of adapting the date itself - where they meet, what they do ALAN adapts his body to an inaccessible place in order to make this date happen.

The happy ending to this play (characteristic to comedies) disrupts the feeling of sympathy or pity for ALAN. Although he does give up on the date, meaning having given up on any possible relationship that could have transpired, a phone call from LINDA saves the day. While this may seem trite, ${ }^{17} \mathrm{I}$ chose a happy ending so as not to cast ALAN as completely powerless in the face of inadequate transit. Lewis warns against a solitary focus on the terrible conditions which the disabled character must either survive or perish. These types of stories invariably reinforce the individual model which "privileges personal responsibility over civic or collective responsibility." (Lewis 2000:99) She contends that disability theatre must show both the individual characteristics of Disabled Peoples themselves along with the social conditions which they continually face. As such, it was

\footnotetext{
${ }^{17}$ Yet another story in which the bell saves the day
} 
equally important not to cast $A L A N$ as a hero. $A$ triumph over these social barriers-would have undercut my attempt to deliver a socio-political challenge. By having to call a cab to get to the date, he is forced to spend $\$ 80$. We don't know if the date ends up being worth the money. Yet, his initial excitement about the date has returned. He does not care about the consequences of spending $\$ 80$. The play ends by exaggerating ALAN's excitement over the date, which is the way the play began.

Lewis identifies two main approaches that disability theatre artists are using to confront the individual model: i) strategic constructionism, which "removes stigma, minimizes difference and attacks hierarchies"; and ii) strategic essentialism, which "emphasizes difference and individual experience and calls for a community based on claimed difference."(2000:95) ${ }^{18}$ She argues that both these approaches confront the individual model in different ways. The former points to the social tragedy of the exclusion of Disabled Peoples, while the latter celebrates the disability experience in terms of identity and empowerment.

Lewis points to artists taking a strategic essentialist approach towards representing disability. These works draw on the ways in which impairment and disability create difference, and thus becomes a source of identity rather than resulting in exclusion. She cites a performance by actor Brad Rothbart. He is sponge bathing his naked Cerebral Palsied body while reciting a lyrical essay by Deborah Abbot. This essay celebrates her post-polio body while showering in a 18 She makes reference to Rosmarie Garland Thomson (1997) in labelling and defining these two main approaches. 
public locker room. According to Lewis, Rothbart interrupts dominant narratives placed on the disabled body "first by presenting the 'deviant' body in a fashion traditionally reserved for beautiful female nudes; then by fusing the subject and object of his desire in his appropriation of the auto-erotic narrative of a disabled woman; and finally by creating, in his identification with the female 'deviant,' an enlarged theatrical body capable of extending beyond the personal to the communal and embracing the audience." (p.107)

In his performance, Rothbart not only accepts his disabled body, but celebrates it as being beautiful. In doing so, he challenges our very notion of what a beautiful body should look like. His body does not need to be fixed or cured. Lewis argues that this breaks the narrative of a "nonconforming body as punishment" by constructing the physically impaired body as being beautiful.

However, I had wanted to establish a relationship between ALAN and the audience that was based on his emotional and physical desire to connect with someone. Within this type of framework, my play falls into the strategic constructionism category. Although I do not ignore the effects of impairment and disability on ALAN's life, my focus is not on how these experiences make ALAN different from non-disabled people. Rather, the plot focuses on how ALAN is excluded from dating and socializing on the basis of impairment and disability. Throughout the play, barriers such as the inaccessible nightclub and the expensive taxi ride are highlighted as increasing ALAN's sense of risk and self- 
doubt over his date with LINDA. Although ALAN expresses self-doubts about his date with LINDA, these can be resolved with the arrival of the bus. The structure of the transit service is framed as the dominant threat to this relationship.

I felt it was important for the audience to get to know ALAN independent of the oppressive structures which he struggles against. This is achieved by framing the story in terms of a romantic comedy. ALAN is portrayed as a normal, ordinary type of guy caught in strange and unusual circumstances. The dramatic tension arises from the ways in which the character acts and reacts to the waiting for the bus, to the inaccessibility of the nightclub, to patronizing attitudes as well as to receiving so much attention from an attractive woman. The use of First-Person Narrative gives the audience insight into ALAN's thoughts and insights, thus establishing an intimate relationship with the character. This again allows us to know the character of ALAN independently from the situation in which he finds himself. 


\section{CHAPTER SIX: CONCLUSION}

Historically, social work has been seen as one of the helping professions. Our practice is aimed at producing a better fit between the individual and their environment, whether it is on the level of direct intervention, community development or policy. As such, the orientation of social work towards theory and research is not only directed at understanding the relationship between the individual and their environment, but also carries a prescription for change.

Analyzing disability as a structural problem requires fundamental changes to theory, research, education, training and practice within social work. A major goal in the writing of this thesis has been to highlight arts and culture as a site of political struggle for Disabled Peoples. Disability artists are engaged in a struggle over political representation and the means of cultural reproduction. It is important to understand this type of struggle in order to be an ally to the disability movement. Disabled Peoples are not only engaged in a struggle over rights and access, but also over meaning and identity. Disability cannot be treated as merely a technical or administrative problem (Finklestein 1994). Such attempts de-politicize and individualize the struggle for equality and Human Rights of Disabled Peoples.

The analysis of my play, Still Waiting for That Special Bus provides a case study of the use of theatre to challenge dominant frameworks which underlie disability oppression. The implications for social work are reflexive in nature which informs 
theory, research, education, training and practice when working with Disabled Peoples.

\section{IMPORTANCE OF THE SOCIAL MODEL}

Disabled Canadians are over-represented when it comes to being dependent upon social services such as subsidized housing and income support. This situation is often not directly related to impairment, but is instead due to structural barriers resulting in poverty and unemployment. The social model arises out of Disabled Peoples' struggle for Human Rights and equality and is in direct opposition to the individualised view of disability. A clear distinction is made between socially constructed disability and bodily impairments. Oppression and inequality are due to structural arrangements which dis-empower people based on mental and physical impairment. The focus of the disability movement is on the removal of these structural barriers.

This thesis has argued that the social model is integral to understanding disability oppression. According to Judy MacDonald, Peter Dunn and Roy Hanes (2003) the past 10-years has seen a growing effort within Canadian Schools of Social Work to frame disability inequality in terms of oppression and power, instead of mental and physical limitations. However, they argue that '[i]naccessibility, lack of accommodation; lack of course material relating specifically to people with disabilities as well as few role models for students and limited faculty research interests in disability [still] represent the present situation in schools of social 
work in Canada." (2003:2) Fewer than 35\% of Canadian schools offer courses specifically related to Disabled Peoples.

Many of these disability-related courses are likely to adopt a rehabilitation framework as opposed to the social model. Such a focus aims to restore an individual to a level of functioning deemed as normal as possible by treating the impairment. While I do not want to deny the benefits of individual treatment, this does not address structural oppression.

The rehabilitative framework is credited with creating a myriad of services for Disabled Peoples at the same time as reinforcing passive citizenship (Oliver 1996). Despite the numerous rights-based claims having been won within areas such as education, employment and transportation, disabled Canadians still face formidable inequality within all major life areas (Valentine et al. 2001). These gains have all been won on a case-by-case basis, and have yielded minimal, if any structural changes. Efforts towards ending oppression explicitly mean changing the structural arrangements which dis-empower Disabled Peoples. Failure to clearly distinguish between impairment and disability carries the great risk of complying with the oppression of Disabled Peoples.

Within theory, research, education and training, social work needs to focus on examining the processes by which people with impairments are marginalized and rendered invisible in order to intervene and adequately challenge oppression. But it is only by reflecting on established theories and practices that social workers 
can begin to address the reproduction of disability oppression. Researchers, educators and practitioners involved in training must include disability within their own areas of study and practice.

Analyses on race, class, gender too often presume able-bodiness. Disability is not seen as being a women's issue (Odette 1993; Meekosha 1998) even though $54 \%$ of Canadians with impairments are women (Grenon 1991). The disability rate among First Nations' Peoples is twice as high (30\%) as among Canadians in general $(15 \%)$. The overwhelming majority of Canadians with disabilities live in poverty. Despite this, it is rare to find Disabled Peoples included among generalized studies on race, class and gender. In view that there has been work and writing done on disability from a social and political perspective, social workers must question the continued marginalization of this work from contributing to the general analysis of power. The on-going omission from theory, research, education, training and practice colludes with the segregation of Disabled Peoples. Generalized theory, research, education, training and practice have recognized the relationship between power, class and gender, as well as (to a lesser extent) recognizing that power is also affected by race, ethnicity, sexual orientation and age. However, these types of analyses are only beginning to include the relationship between power and ability.

Social workers must also approach disabled individuals as being enmeshed within a multitude of power structures. Mackelprang (1998) argues that social 
workers and professionals who work with Disabled Peoples must examine their own views of impairment in order to adequately address disability issues.

Understanding the dynamics of oppression involves recognizing that people with disabilities are: 1 . denied the privilege associated with not being disabled 2 . exploring and understanding internalized forms of devaluation and self-hatred 3 . understanding the "prevalence of stereotypes and beliefs which make it difficult for people with disabilities...to form alliances with each other and with other minority groups" (Onken and Mackelprang, 1997, p.5, quoted by Mackleprang 1998:14)

Feeling alone and being the only one is prevalent among the disability population. Even the experience of a supportive family can reinforce disability as being an individual problem (Shakespeare et al. 1996:50). Unlike other minority groups, Disabled Peoples are not born into families of the same social status. There is no connection between identifying with one's family and develøping a critical disability-consciousness. Being treated as a normal family member can mean ignoring one's disability status, as the following quote exemplifies -

[My family has] come to accept the fact that I'm the same as anyone else, can do as well as anybody else, which had its advantages which was not being mollycoddled. The disadvantage was I was never taught anything about disability and the wheelchair, about disability and identity...I was normal like everyone else and I had the opinion that I was better than disabled people, and I wasn't disabled (from an interview quoted in Shakespeare et al., 1996:50)

Each of my courses within the Carleton University School of Social Work has approached social inequality as fundamentally arising from a lack of access to 
resources due to the structure of social relations. Inequality by class, gender, race, age, ability, and sexual orientation are structural problems requiring structural change rather than requiring individualized solutions. However, it has been as much of a problem to change the individual to the neglect of social structures as it has been to change these structures without changing individual values and beliefs (Kideckel 1998). In order to address structural barriers we, as structural social workers, must work with individuals. It is not enough to only understand that individual problems are caused by structures.

I had been extensively involved in a community organizing campaign around improving the level of accessible public transit within Ottawa-Carleton. This campaign brought to light the entangled connections between changes at the policy level and changes at the individual level. While people may have been unsatisfied with the current level of accessible transit, most viewed any level of service as a privilege rather than a right. In order to demand increased levels of accessible transit, we had to work on changing these perspectives on an individual level.

The structural approach to social work presented me an opportunity to learn how to bridge changing the individual with changing the environment. My experiences organizing the public bus campaign was, in fact, a crash course on the intertwining of direct intervention, community development and policy change. My 
work on accessible transit showed that individuals with impairments had to redefine their service as being a right, not a privilege.

Joy Lenny (1994) asks the question 'Do disabled people need counselling?' and frames it in terms of the age-old dilemma of 'Do you change the individual or do you change society.' Lenny concludes that counselling disabled people is not about "someone's impairment or their disability, but about helping them to make sense of the relationship between the two." (p. 239) In discussing the question of counselling disabled people, Lenny relies on the social model in making a distinction between impairment and disability. But in order to have this type of understanding, social work must problematize the relationship between ability, power and identity at all levels of theory, research, education, training and practice.

Reading personal accounts from disabled men and women, as well as from disabled students and professionals would contextualize what it means to live with impairment within the current structure of social relations. This would bring ability into our understanding of identity. But bringing impairment and disability into a structural analysis of power cannot be limited to understanding difference and identity. Just as the study of race focuses on 'whiteness' and what it means not to be white in a racist society, the study of impairment necessarily focuses on the construction of able-bodiness and what it means not to be able-bodied in an 
ableist society (Davis 1995). A disability analysis carries with it a prescription for re-structuring society to address power imbalances.

For example, I have a speech impairment - meaning I speak differently than what is considered normal. My speech pattern is slower than average, and is slurred. Ironically, I am given less space to express myself - not because I take more time to say the same thing - but because, particularly in informal situations, people are less likely to give me the same amount of time and floor-space to talk that they would give to some one without a speech impairment. Within our culture, in order to express yourself, you need to jockey for position and compete to be heard (Rupert, 1996). Thus, this is what disables me. People with heavy accents can experience this as well. Looking at disability in this way begins to connect people across previously differentiated groups. Rather than analyzing disability as an intrinsic difference within the individual, it needs to be approached as involving particular sets of structural relationships which disadvantage people with impairments. This shifts the focus away from changing my particular way of speaking to changing certain aspects of our culture. Yet, doing so is often met with resistance. People with the ability of being able to speak up are given the privilege of having the space to talk and express themselves. Structural change challenges these types of privileges. 


\section{DISABILITY ARTS AND POLITICAL STRUGGLE}

Abbas et al. argue that disability arts exposes audiences to radical discourses on disability who may not otherwise engage with these sets of issues (2004:2). This has been demonstrated through a case analysis of my play. Still Waiting for That Special Bus generates discussion around (i) transportation and physical access issues; (ii) attitudes and prejudice that Disabled Peoples are passive and need our charity; (iii) the distinction between physical and mental impairment and socially constructed disability; and, (iv) structural and attitudinal barriers to sexuality for Disabled Peoples.

The play further challenges mainstream representations of Disabled Peoples by not providing any medical explanation of ALAN's impairments. Several references are made to the character's impairments throughout the play, yet it is all done in the context of his date with LINDA. For example, ALAN talks about LINDA having to get his walker out of the trunk of the taxi on the way home. He talks about having to crawl up a flight of stairs to get into the night club where he is to meet LINDA. This reflects common everyday experiences of Disabled Peoples. Yet these issues are introduced within the context of ALAN's emotional and sexual desires. In this way various structures are revealed which isolate ALAN and act as barriers to getting to his date. This frames ALAN's issues in terms of structural arrangements, rather than due to his impairments. Within my play ALAN's anger is not at being unable to walk. Rather, his anger is directed towards the social isolation due to structural and attitudinal barriers. 
This play challenges the idea that Disabled Peoples are either asexual or sexually deviant. Shakespeare et al. argue that the social model and the politicization of disability issues are both crucial in guiding Disabled Peoples' experiences of love and relationships. Thus in my play I make a direct link between ALAN's pursuit of an intimate relationship with LINDA and the attitudinal and structural barriers which he faces.

Marita McCabe's (1999) comparative study between disabled and non-disabled individuals found that there were lower levels of sexual experience and knowledge, and a higher degree of negative attitudes towards sex among her disabled respondents. She also found that Disabled Peoples have less access to both formal and informal sex education. She argues that this is partly because the sexual needs of Disabled Peoples are not recognized. McCabe noted resistance from attendants and professionals who work with Disabled Peoples to the conducting of her survey. She indicates that this reflects an overprotectiveness of the sexuality of Disabled Peoples that is reflected within the literature on sex, relationships and disability.

Tim Stainton \& Karen Swift (1996) argue that social work education must be focused on changing power structures which reproduce inequality. They warn that courses which adopt rehabilitative paradigms have the danger of reinforcing dominant frameworks of disability. Special care must be given to critically 
analyzing these mainstream views. "Put another way, is the voice of the course that of the oppressor or that of the oppressed?" (p. 85)

The Disability Arts and Culture Movement represent a voice which is critical of dominant paradigms of disability. Fries argues that "Beyond proclamations of pride, deaf and disabled people have been uncovering or formulating sets of alternative values derived from within the deaf and disabled experience...They declare that they prize not self-sufficiency but self-determination, not independence but interdependence, not functional separateness but personal connection, not physical autonomy but human community." (1997:9) Images surrounding impairment and disability are being deconstructed and reconstructed within disability arts.

Mullin (2000) argues that artworks do not affect our beliefs and values in a predetermined way. It is impossible to predict the exact influence a particular work will have upon its audience. Moreover, Mullin states that, because audiences are not uniform in their own beliefs and values, reactions and responses to particular works will also not be uniform. The receptions to works of art are strongly influenced by the audience's or viewer's own standpoint. Mullin argues that this ambiguity in response is a positive feature. She compares our experience of a piece of art to our encounters of others, of actual human beings.

When we respond to an artwork we are in contact with another, and we can let the other speak to us and attempt to listen. There are no constraints on our response, and no way to guard against 
misinterpretation, which can be dangerous, but this may also help us tolerate ambiguity and ambivalence. When we respond to art we are often prepared to be alienated and moved, disoriented and intrigued. We do not feel impelled either to dismiss the work as too different from us, or cover over its differences from us. Both of these moves are too often characteristic of social encounters where we do not feel kinship with the other, and therefore do not feel at ease. (p.132)

The comparison made between experiencing art and encountering another perspective can be powerful when examining the political significance of art. The above quote opens up the possibility that, while we might not be willing to listen or be open to a perspective different from ours, we nonetheless are willing to suspend this resistance when viewing or experiencing art. In this type of analysis, art then becomes a window through which oppressed groups can make their voices heard.

Audience reception significantly impacts the political power of art. Abbas et al. argue that audiences must gain a greater understanding of the complexities of disability oppression and identity in order for the disability arts movement to grow and mature. They draw the conclusion that that "because these performances are reciprocal, both sides of the relation require attention and support" (2004:2). The political strength of disability arts does rest on building a relationship with the audience.

Although my play clearly works better for some audiences than others, as the playwright and performer, I feel the production achieves what I had set out to do. It tells my own story about navigating different structures of oppression. In telling 
this story, I hope to promote discussion and perhaps even political action around the issue of parallel transit. I have performed for TAN (Transportation Action Now) and was invited precisely because of the way my play deals with the subject matter. Many disabled people came to see my show during my tour across Canada again because of the way my story frames disability. One of the greatest receptions I've received was in Bermuda for Access Awareness Week. For many, disabled and non-disabled alike, it was their first time seeing a disability arts performance and their first time seeing disability framed in that way. Hopefully the viewing of my play is a small step in towards ending disability oppression. 


\section{REFERENCES}

Abbas, Jihan, Kathryn Church, Catherine Frazee, Melanie Panitch, Lights...Camera...Attitude! Introducing Disability Arts and Culture, Ryerson University, Toronto, 2004

Archambault, Francois, 15 Seconds (transl. by Bobby Theodore), Talon Books; Vancouver, 2000

Barnes, Colin, Geof Mercer, Tom Shakespeare, Exploring Disability: A Sociological Introduction, Blackwell Publishers, Malden, Massachusetts, 1999

Barnes, Colin and Geof Mercer, "Disability Culture: Assimilation or Inclusion?" in Handbook of Disability Studies, Gary L. Albrecht, Katherine D. Seelman, and Michael Bury, eds., Sage Publications, California, 2001

"Breaking the Mould? An Introduction to doing disability research", in Doing Disability Research, Colin Barnes and Geoff Mercer, eds., The Disability Press, University of Leeds, 1997, pgs. 1-14

Barry, Shelley, "Politicizing Disability Through Arts and Culture - An interview with Mandia Mabila", http://www.disabilityworld.org/04-05_02/arts/mandla.shtml, 2002

Bedford St. Martin's, Glossary of Literary Terms, web document http://www.bedfordstmartins.com/literature/bedlit/glossary_f.htm

Breckwaldt, Sue, "Dating \& MS: When your disability is not always visible, when and how much do you tell a potential significant other about it?", in Paraplegia News, February 1989, pgs. 23-25

Boal, Augusto, Theatre of the Oppressed (transl.), Urizen Books, USA, 1979

Bowe, Frank, “Accessible Transportation”, in Crewe, Nancy M. and Irving Kenneth Zola and associates, eds., Independent Living for Physically Disabled People, Josey-Bass, San Fancisco, Calif, 1983, pgs 205-218

Callahan, John, Don't Worry, He Won't Get Too Far On Foot, First Vintage Books, 1990

Cameron, David, and Fraser Valentine, "Comparing Policy-Making in Federal Systems: The Case of Disability Policy and Programs - An Introduction", in Disability and Federalism: Comparing Different Approaches to Full Participation, David Cameron and Fraser Valentine. Eds., McGill-Queen's University Press, Montreal, 2001, pgs. 1-44 
Cordingly, Kim, Annotated Bibliography on Life Writing and Disability, http://www.as.wvu.edu/ lbrady/annobib-kim.html, 2000

Corbett, Jenny, Bad Mouthing: The Language of Special Needs, Falmer Press, London, Washington D.C., 1996

Covey, Herbert C., Social Perceptions of People with Disabilities in History, Springfield, Illinois, 1998

CT, Still Waiting for That Special Bus, Eye Review, Eye Weekly, Toronto, http://www.eye.net/fringe/00/display.asp?show $=71,2000$

Darke, Paul, "Understanding Cinematic Representations of Disability", in The Disability Reader, Tom Shakespeare, ed., Redwood Books, U.K. 1998, pgs. 181200

"Beyond the U Bend", in Disability Arts In London (DAIL) Magazine, London Disability Arts Forum, London, England, Summer 2004, Issue 182, pgs. 15-17

Deloach, Charlene P., "Attitudes Toward Disability: Impact on Sexual Development and Forging of Intimate Relationships", J of Applied Rehabilitation Counselling, Vol. 25, No. 1, Spring 1994, pgs. 18-25

Edelman, Murray, From Art to Politics: How Artistic Creations Shape Political Conceptions, University of Chicago Press, Chicago, 1995

Ferris, Jim, "Uncovery to Recovery: Reclaiming One Man's Body on a Nude Photo Shoot", Michigan Quarterly Review, Vol. 17, No. 3, Summer 1998, pgs. 503-518

Finklestein, Vic, "Disability: a social challenge or an administrative responsibility?", in Disabling Barriers - Enabling Environments, John Swain, Vic Finklestein, Sally French, and Michael Oliver, eds., Sage Publications, California, 1994, pgs. $34-43$

Frazee, Catherine, "Notes for keynote added by Catherine Frazee", available at http://www.s4dac.org/festivals/kickstart/2004/catherine_frazee_keynote.html, 2004

Fries, Kenny, "Introduction", in Staring Back: The Disability Experience from the Inside Out, Kenny Fries, ed., Plume, New York, N.Y., 1997

Fulcher, Gillian, Disabling Policies?: A Comparative Approach to Education, Policy, and Disability, Falmer Press, New York, 1.989 
Gallasch, Keith, "Paralympic Arts: Invincible Summer", in Real Time, Issue 40, December 2000 - January 2001, Australia, http://www.realtimearts.net/rt40/gallaschpara.html

Gorman, Rachel Jean Katharine, Class Consciousness, Disability, And Social Exclusion: A Relational/Reflexive Analysis Of Disability Culture, PhD Thesis, OISIE, Toronto, 2004

Gadacz, Rene, Re-Thinking Disability, University of Alberta Press, Edmonton, 1994

Gilson, Stephen French and Depoy, Elizabeth, "Theoretical Approaches to Disability Content in Social Work Education", J of Social Work Education, Vol. 38, No. 1 , Winter 2002, pgs. $153-165$

Greater Vancouver Transit Association, Development of the Accessible Transit Strategic Plan, Minutes from the board, http://www.translink.bc.ca/files/board_files/meet_agenda_min/2005/04_20_05/4. 1accessibletransit.pdf, 2005

Grenon, Gordon Lee, Stigma at Work, Masters' Thesis, Dept. of Sociology, UBC., Vancouver, 1991

Haller, Beth, "The Misfit and Muscular", J of Popular Film and T. V., Vol. 7-22, No., 1, 1993, pgs. 142-149

Hanes, Roy, "Social Work with People with Disabilities", in Steven Hick, Social Work in Canada: An Introduction, Thompson Educational Publishing, Toronto, 2002, pgs. $217-235$

"Generalist and Specialist Social Work Education and People With Disabilities: Some Points For Discussion", unpublished, 2003, pgs. 1-12

Hevey, David, The Creatures Time Forgot: Photography and Disability Imagery, Routledge, New York, 1992

"From Self Love to the Picket Lines", Disability and Society, Vol. 8, No. 4, January 1993, pgs. 423-429

Hooks, Bell, Art on my Mind: Visual Politics, The New Press, New York, 1995

Kideckel, Harriet, Structural Social Work Direct Intervention Skills, MSW Paper, Carleton University, unpublished, 1998

Klein, Bonnie Sher, Slow Dance: A Story of Stroke, Love and Disability, First Vintage Books Canada, 1997 
Lenny, Joy, "Do Disabled People Need Counselling", in Disabling Barriers Enabling Environments, John Swain, Vic Finklestein, Sally French, and Michael Oliver, eds., Sage Publications, California, 1994, pgs. 233-240

Lewis, Victoria Ann, "The Dramaturgy of Disability", in Points of Contact:

Disability, Art and Culture, Susan Crutchfield and Marcy Epstein, eds., University of Michigan Press, Ann Arbor, 2000, pgs. 93-108

Linton, Simi, Claiming Disability: Knowledge and Identity, New York University Press, New York 1998

Longmore, Paul, "The Second Phase: From Disability Rights to Disability Culture", The Disability Rag, September/October, 1995, pgs. 4-11

MacDonald, Judy, Peter Dunn and Roy Hanes, Disability: From Curriculum to Accommodations, A Decade of Reflections, 2003, Paper presented at the Social Sciences and Humanities Research Congress. Halifax, Nova Scotia.

Makelprang, R., Disability: A Diversity Approach in Human Science Practices, Brooks Cole Publishing, California, 1998

Makelprang, R., and Salsgiver, R., "People with Disabilities and Social Work", Social Work, 41(1), 1996, pgs. 7-14

McCabe, Marita, "Sexual Knowledge, Experience and Feelings Among People with Disability", Sexuality and Disability, Vol. 17, No. 2, 1999, pgs. 157-170

Meekosha, Helen, "Body Battles: Bodies, Gender, and Disability", in The Disability Reader, Tom Shakespeare, ed., Redwood Books, U.K. 1998, pgs. 163180

Mitchell, David T. and Sharon L. Snyder, "Talking about Talking Back:

Afterthoughts on the Making of the Disability Documentary Vital Signs: Crip Culture Talks Back", in Points of Contact: Disability, Art, and Culture, Susan Crutchfield and Marcy Epstein, eds., University of Michigan Press, Ann Arbor, 2000, pgs. $197-217$

Moreau, Maurice, "Empowerment through Advocacy and ConsciousnessRaising", J of Sociology and Social Welfare, 17(2), 1990, pgs. 53-67

Morris, Jenny, Pride Against Prejudice, The Women's Press, London, England, 1991

Mullen, Amy, "Art, Understanding, and Political Change", Hypatia, 15(3), pgs. 113-139 
Nathenson, Ian, Bus Best Ride at Fringe, The Ottawa Sun, June 25, 1999, pg. 34

Newman, W., Social Research Methods: Qualitative and Quantitative Approaches ( $3^{\text {rd }}$ ed), Allyn \& Bacon, Boston, 1997

Norden, Martin E., The Cinema of Isolation: A History of Physical Disability in the Movies, Rutgers University Press, New Jersey, 1994

OC Transpo, Survey of Demand for Transportation by Persons with Disabilities and a Recommendation for Demand Management, IBI Group, Nelson/Nygaard Consulting Associates, HLB Decision Economics, http://www.octranspo.com/admin_menue.htm, June 2001

Odette, Francine, Women with disabilities: The "Third" sex; the experience of exclusion in the movement toward equality, MSW Thesis, Carleton University, Ottawa, 1993

Oliver, Michael, "Emancipatory Research: Realistic goal or impossible dream?" in Doing Disability Research, Colin Barnes and Geoff Mercer, eds., The Disability Press, University of Leeds, 1997, pgs. 15-31 Understanding Disability: From Theory to Practice, Macmillan London, England 1996 1990

The Politics of Disablement, Basingstoke:Macmillan, London, England,

Oliver, Michael and Jane Campbell, Disability Politics: Understanding Our Past, Changing Our Future, Routledge, New York, 1996

Pointon, Ann and Chris Davies, eds, Framed: Interrogating Disability in the Media, British Film Institute, London, England, 1997

Rager, Barbara, "MASC Artist Educates Through Humour and Drama in Schools: A Review of Still Waiting for the Bus - Alan Shain's One Man Show", in MASC News, Spring 2002, pg. 1

Rupert, Ross, Returning To The Teachings, Penguin Books, Toronto, 1996

Sandahl, Carrie, "Ahhhh Freak Out! Metaphors of Disability and Femaleness in Performance", Theatre Topics 9.1, 1999, pgs. 11-30

"Considering Disability: Disability Phenomenology's Role in

Revolutionizing Theatrical Space", J Dramatic Theory and Criticism, Spring 2002, pgs. 17-32

Shain, Alan, Still Waiting for That Special Bus, Smashing Stereotypes Productions, 2000 
Shakespeare, Tom, "Researching Disabled Sexuality", in Doing Disability Research, Colin Barnes and Geoff Mercer, eds., The Disability Press, University of Leeds, 1997, pgs. 177-189

Shakespeare, Tom, Kath Gillespie-Sells and Dominic Davies, The Sexual Politics of Disability: Untold Desires, Cassell, New York, 1996

Shepherd, Thomas, Getting to the Heart: The Role of Frontline Workers in Supported Living, MSW Thesis, Carleton University, Ottawa, 2000

Simpson, David, "A Literary Lexicon", DePaul University, Chicago, web document, available at http://condor.depaul.edu/ dsimpson/awtech/lexicon.html

Stainton, Tim and Karen Swift, "Difference and Social Work Curriculum", Canadian Social Work Review, Vol. 13, No. 1, Winter 1996, pgs. 75-87

Statistics Canada, A New Approach to Disability Data: Changes Between the 1991 Health and Activity Limitation Survey (HALS) and the 2001 Participation and Activity Limitation Survey (PALS), 2001

Education, Employment and Income of Adults With and Without Disabilities - Tables, 2003

The Daily, Tuesday, January 21, 2003

Stone, Deborah, A., The Disabled State, Temple University Press, Philadelphia, 1984

Swain, John and Sally French, "Towards an Affirmation Model of Disability", Disability and Society, Vol. 15, No. 4, 2000, pgs. 569-582

Titchkoksy, Tanya, Disability, Self and Society, University of Toronto Press, Toronto, 2003

Thomson, Rosmarie Garland, "The Beauty and The Freak", in Points of Contact: Disability, Art, and Culture, Susan Crutchfield and Marcy Epstein, eds., University of Michigan Press, Ann Arbor, 2000, pgs 181-196

Extraordinary Bodies: Figuring Physical Disability in American Culture and Literature, Columbia University Press, New York, 1997

Tolan, Kathleen, "We are not a metaphor", in American Theatre, Vol.18, N4, 2001, pgs. $16-20$

Torjman, Sherri, "Canada's Federal Regime and Persons with Disabilities", in Disability and Federalism: Comparing Different Approaches to Full Participation, David Cameron and Fraser Valentine. Eds., McGill-Queen's University Press, Montreal, 2001, pgs. 151-196 
Walker, Pamela, "Artists with Disabilities: A Cultural Explosion", 1998, http://nadc.ucla.edu/library/ArtistswithDisabilitiesPamWalker.pdf

Wendell, Susan, "Towards a Feminist Theory of Disability", in The Disability Studies Reader, Lennard J. Davis, ed., Routledge, USA, 1997, pgs. 260-278

Wishart, Cynthia, Storms and Illuminations: 18-Years of Access Theatre, Emily Publications, 1997

World Health Organization, ICF Introduction, 2001

Wikipedia The Free Encyclopedia, web document, available at http://en.wikipedia.org/wiki/First-person_narrative, 2005

Yegidis, B. L. and Weinbach R. W., Research Methods for Social Workers, $2^{\text {nd }}$ ed., Boston: Allyn and Bacon, 1996

Yoshida, Karen K., "Intimate and Marital Relationships: An Insider's Perspective", Sexuality and Disability, Vol. 12, No. 2, 1994, pgs. 179-189

Zola, Irving Kenneth, "Developing New Self-Images and Interdependence", in Crewe, Nancy M. and Irving Kenneth Zola and associates, eds., Independent Living for Physically Disabled People, Josey-Bass, San Fancisco, Calif, 1983, pgs. $49-59$ 


\author{
APPENDIX A - STILL WAITING FOR THAT SPECIAL BUS \\ written and performed by Alan Shain $(2000$
}

ACT ONE: SCENE ONE (The scene is evening in the living room of Alan's apartment. It's in a mess, with clothes and books and garbage strewn everywhere. At center-stage is a worn easy-chair with a side-table. There is a phone on the side-table and a small radio among several books and papers Alan's walker is parked center-stage-left with crumpled clothes hanging off of it.)

ALAN It';s Friday night, and once again I'm stuck sitting in my apartment and waiting, waiting for my bus to show-up. You see, I did my bit. (Jumps off the chair onto his knees. Moves on knees to down-stage-centre) I dragged myself out of bed early yesterday morning - one whole day ago to - book that special bus - Para Transpo. They better pick me up now, because I've got an incredibly hot date to get to! (Yells excitedly. Picks a shirt up off the floor. Twirls it around over his head and throws it.)

(Continues to address the audience) It's our first time going out together, so I've gotta do EVERYTHING I can to impress her, because this woman may be the one - the one who falls completely and madly in love with me. I've gotta put my best foot forward (looks down at knees) - or my best knee forward (sits with 1-knee out) so that she won't be able to resist coming home with me tonight!

(Arms out-stretched, singing) THERE'S GONNA BE LOVE IN THE AIR, TONIGHT!

(Puts arms down, goes back to kneeling on both knees) O.K., maybe I won't sing. That might make her cry. I hate when people feel sorry for me.

I was on this one date where I was telling her about how my brother and I used to fight a lot. A big tear welled up in her eye as she said 'Oh you poor poor baby.' (Pause) What the hell was that? It was me beating up my brother!

I fight off sympathy where ever and whenever I can. (Pause) But sometimes sympahty works in my favour. I can use it to get what I want.

(Starts talking excitedly) Once I had 3-women take me home - count them, $1,2,3$ women! When they got me in my door, one of them asked if I needed any help to get into bed. (Pause, mimicking answering the question) Actually - now that you mention it - yes, I do need some help. 
ALAN (Continuing to tell the story) So they line-up my wheelchair beside my bed. Two of them grab one of my legs each. One grabs me under my arms and together the three of them lift and lay me gently on my back. One of them then asked if I needed help to get undressed.

(Mimicking his answer to then, yells excitedly) YES!

(Finishes telling the story in a disappointed tone) She picked up my phone and started dialling her boyfriend saying he would be happy to give me a hand. And when he came over he did not have much sympathy towards me.

I think I give women the wrong first impressions. Women see how uncoordinated I am on my feet and think 'God knows the damage he would do in bed!'

Hopefully, my date tonight will find out that I am actually extremely gentle - aside from being a sensual hot-bed of sizzling sexual delights! (Yells excitedly while lifting up his shirt to show-off his chest to the audience)

(Pauses, slowly surveys the state of his living room.) Actually, my place is a goddamn mess. I should clean up in case she does come home with me tonight. I want to be prepared. (Pulls out a big duffle-bag from under the side-table. Starts throwing everything into the bag)

(Talks to the audience while continuing to stuff the bag) My date was a bit surprised when I said 'We're gonna go dancing tonight.' I guess she assumed we'd just be, you know, sitting around - watching a movie or drinking coffee somewhere. But she said she would love to go dancing with me, and that I am always impressing her with what I can do.

(Pauses to chuckle. Then continues to stuff things into the duffle-bag. Picks up a T-shirt and looks at it. Laughs and addresses the audience) Check this out. My favourite T-shirt. (Shows the audience the T-shirt while telling them what's printed on its front) 'Piss-on-Pity.'

(Laughs while stuffing the shirt into the duffle-bag) Wouldn't want her to see that shirt. At least not yet. I hardly even know her. (Pause) Actually, I don't know her at all. We just met 3-nights ago at this party. It was the kind of party where - you know - everyone there seemed to know everyone else - so it was me and her on the outskirts of this 'party' we were supposedly involved in. 
ALAN She saw me, walked over, extended her hand, said "Hi, my name is Linda." and sat down. (Has walked to down-stage-left to mimic Linda approaching him)

I hardly remember what we talked about. I just remember it was all about me. She kept saying "Wow! I'm so impressed!" - so naturally I kept on talking.

(Continues stuffing duffle-bag. Then stops when he suddenly remembers something. Laughing) Oh ya! I started telling her that I'm sick of my job. And she stops me in mid-sentence and exclaims, "You work?!"

(Mimicking his answer to her) Well, I need to eat, and I like to drink, so I pretty much have to work.

That kind of question usually pisses me right off. But she was cute. And I liked the way she laughed at herself afterwards for even asking such a question.

(Continues cleaning up by stuffing everything into the duffle-bag) We ended up sharing a cab home together because we were both going the same way. All the way home I kept trying to figure out how to meet this woman again, because otherwise what was the whole point of meeting her in the first place? But nothing was working By now the cab was already at my place and she was getting my walker out of the trunk. So I decided to go for it. As I got out of the cab I took a deep breath

Night-time lighting down-stage right, remainder of stage dark

ALAN (Moves on knees to down-stage right. Mimicking talking to Linda, nervous) I-I think we should go out. Wh-What's your phone\#?

(Addresses audience) She was a little taken aback. (Turns to face leftdown-stage, mimicking Linda's answer while backing up on knees) My number? I ... um ...I don't have a pen, or a piece of paper.

(Addresses audience) Neither did I. (Turns to face down-stage right, mimicking his response to Linda. Attempting to act confident) That's OK. Just tell me your phone number and I'll repeat it over and over again to myself - out-loud - until I get into my apartment and write it down.

(Mimics Linda's reply, nervous dis-belief) Um...alright....224- 4675.

ALAN (Addresses audience. Astonished) She gave it to me! She gave me her number! (Turns to face downstage-right. Mimics excitedly talking to Linda) 224-4675! 224-4675! OK, bye! I'll call you tomorrow! 
As ALAN crosses from down-stage right to center-stage left, dim lighting across entire stage

(Mimicking being excited while describing scene to the audience) I'm walking up to the front door of my building. 224-4675. 224-4675. I get into my lobby. Cross to the elevator. (Turns to face down-stage right) I press the button for my floor.

Whole stage BLACK. SPOT on ALAN center-stage left)

And the elevator door slowly closes. (Recites excitedly) 224-4675! 2244675! (Addresses audience) The elevator moves up half a floor and then stops! Dead! Nothing.

(Looking around, nervous) 224-4675. Hey! (Jumping) 224-4675. (Yells) Hey, what the hell is going on? 224-4675. Somebody help!

(Addresses audience) A voice from above spoke, 'Is there a problem down there?'

(Looking up) YES! 224-4675. I'm stuck in the elevator and I need a pen! QUICK!

Lighting returns to a general wash.

ALAN (Moves to down-stage center. Addresses audience) I don't know what happened next, or how I even got out of the elevator. The next thing I remember was waking up in my apartment in the morning to find this phone number scrawled all over the place. Seven times in my bedroom, five times in my living room, twice in my kitchen, once on the back-side of my apartment door. And they were all the same number, so that was a good sign.

The bad sign was that, in my desperate attempt to engrave her number onto my brain, I had completely forgotten her name.

What was I gonna do? What could I do? I HAD to call this number. I played over what I could say if her room-mate answered the phone. (Mimicking talking nervously on the phone) "Hi. My name is Alan. Is there some one living there that might know me?"

ALAN (Excited) Luckily, it was her who picked up the phone There was a bit of a pause in her voice, then she said, 'Oh, hi! It's you, Alan! I'm so glad you called!' 
It was the right woman, so I played a little trick to get her name. (Mimicking being on the phone) I called the number I thought I remembered, but how do I know it's really you?

(Relieved) She laughed, and said, "Of course it's the right number! It's me - Linda! I'm so impressed with your memory!"

(Yells excitedly) YES! And now if that bus of mine ever shows up I can impress her even more with my dancing! (Does a little dance on his knees, then crawls down-stage left to look out of doorway)

(While crawling back to center-stage to sit on the chair) They're already 20-minutes late. (Exasperated) The bus said they would pick me up at 8, and I'm supposed to meet Linda at 9. That gives them a whole hour to get me there.

You would think they could do that much for me - especially on a night like tonight! (Places hand on phone, thinks a moment, then starts dialling)

(On the phone) Hi. My number is 1443, I have an 8 o'clock and I'm wondering where it is. (Pause, frustrated) Ya, I know all about the half hour window. (Pause) Ya, I know that an 8 o'clock means that you will pick me up anywhere between 8 and 8:30. But can you just check that there is actually a bus on the way for me? (Pause) What?! I can just be patient? Fine! Bye! (Hangs up)

(Addresses audience, frustrated) Just be patient. Ya, we can all just be patient as if we're waiting for a big gift from Santa Claus! And we should be so grateful for that we even get to go out!

(Pause, chuckles to himself. Addresses audience) I told Linda my special bus joke - about how in Ottawa all my special buses used be run by Laidlaw. So I was getting picked up by the same people who collected all the garbage in the morning. (Feigning being grateful) Boy, does that ever make me feel special.

(Chuckles) Linda laughed at that one. (Pause. Downcast) But then she made a comment. She said "Alan, I think you're special."

ALAN (Gets off chair onto knees. Moves down-stage center. Angry) I didn't like that comment. (Pause) It felt condescending, but what could I say? I wanted to go out with her!

Who am I kidding? Linda wouldn't ever wanna sleep with me! She probably can't even imagine sleeping with a guy like me! I'm just some 
kind of show to her - some one to make her laugh and entertain her a bit, but no one she feels she could ever be intimate with.

(Pause. More anger) I know what will happen tonight! I'll get there, and then she'll insist on buying all the drinks. I invited her out and she won't let me pay for anything. That's how I'll know! That's how I'll know that Linda doesn't think of this as being a real date!

(Gives the duffle-bag an angry push. Then pauses to think. Cheering up and becoming hopeful) But I like Linda. (Addresses audience while trying to convince himself) When we shared that cab home the other night, and I was fumbling for my wallet to pay for my share of the cab, she let me pay. And then she jumped back into the cab and took off.

She didn't wanna walk me across my own street, make sure I was 'safe.' That gave me a good feeling about her.

(Pause. Laughs) Listen to me talking! I'm making WAY too much out of Linda. I'm falling for some one who let me pay for my own cab! Alan, get a grip! .

(Continues stuffing duffle-bag) I thought about taking a cab tonight. It was so awkward asking Linda where and when we were gonna meet 3 whole days before the actual date. She wanted to wait and set all that up this afternoon, saying that she was more of a spontaneous type.

But that kind of spontaneity would cost me about 40-dollars in cab-rides and I only have 40-dollars I can really spend tonight. I mean, I want at least some money I can spend on the actual date. So I decided to let Linda in on the inner workings of Handi Transit (Mimics an eerie sound effect. Taking an informative tone) If I wanna go out on a Friday night - tonight I have to know exactly where I'm going and at what time by Wednesday night, so that I can wake-up early Thursday morning to book the bus, so that hopefully I can actually go out on Friday.

ALAN I didn't want her to get the impression that it was me who wanted to plan out every single little detail of our date - although I must admit that I have planned out exactly how I want this date to go tonight.

(Excited) Me and Linda, we'll meet at the bar at 9 o'clock (looks at watch) Well, hopefully. The band doesn't start until 9:30. So we'll grab a table, sit down, and I'll order us a couple of drinks.

Lights have changed to simulate inside a dance bar. Dim red-lighting with slow strobe over stage with SPOT center-stage on chair and a SPOT down-stage left. 
ALAN (Smiling) And we"ll - chat. You know, I'll schmooze her up a bit - make her laugh and feel comfortable with me. Then the band will start and I'll turn to her and say "Hey Linda, we came here to dance, so let's dance."

(Gets off chair, starts crawling downstage-left towards walker) And I won't wait for her to say 'Yes' or 'No.' I'll just get up, (stands-up with walker) grab my walker and go right onto the dance floor..(scurries with walker to SPOT downstage center. Smiling) And I know she'll be following right behind me.

(starts dancing with his walker) Now I'll take it easy on her the first 2songs. You know, let her get used to dancing beside me. (Pause. Dancing slowly) But by the beginning of the third song - around 9:47 - I'll start showing off some of my real moves! (Dances faster with walker) I'll start swinging my hips, and accidentally make physical contact - oops! (Stops dancing suddenly) Just to see how she reacts.

(Continues dancing) Then we'll keep on dancing, until 3-songs later - at about 10:12 - when my hands will suddenly leave my walker - woo - and grab hold of her hands. So now we'll be dancing face-to-face, and I'll start pulling her closer and closer so that right around 10:30 we'll be dancing cheek-to-cheek.

(Stops dancing) Now hopefully the band will cooperate with my plan by playing one of those slow romantic songs, and I'll stare intensely - but sweetly - into her eyes. Soon, we should be starting to kiss.

(Throws up his arms and lets out a Whoop! Loses his balance and falls to the floor. Laughs) I better not fall down on Linda. That might be a bit much for her to take on our first date. (Pause) Although I could say, (Lays on his back holding his arms out and mimicking amazement) "Hey look, Linda, I'm already falling for you."

Lights back to a general wash. ALAN laughs, then picks himself up to a kneeling position, and crosses down-stage right to look for his bus.

ALAN OK., this bus is really late now. (Looks at his watch) Jeez! It's ten past 9! (Hurriedly crawls to center-stage and sits on the chair) I should be at the club by now! Where the hell are they?

(Anxious, dials phone. Talking on the phone) Hi, my \# is 1443 , I have an 8 o'clock pick-up! Why are you so late? Hello? Hello? (Addresses audience) Now I'm on hold! (Back to phone.) Hello? Hello? Some one talk to me! 
(Holds receiver out from his ear) I got this elevator music playing in my ear! (Yells into the phone) Come on people! Answer the stupid - oh hi. (Pause) You'll send another bus? What happened to the first one? (Pause) Too many passengers on board? (Pause). I don't care that everyone wants to go out on a Friday night. (Pause) No, I don't care what else is going on downtown tonight! Just get me to my goddamn date. (Pause) Am I gonna get there before midnight when I have to come right back home again? (Pause) Hello? Hello? (To audience) he hung up! (Slams phone)

(Stares out at audience, bewildered) What am I supposed to do now? (thinks, begins to re-gain composure, hopeful) Hey! I should take a cab! I mean, so what if I spend 40-bucks on cabs and another 40 on Linda! At least I would have gone! I would have met Linda, and I would have found out what she really thinks about me. Right?

(Thinks, starts getting downcast) As if I really need to go to find that out. (Starts taking off shoes, talking to himself, consoling) C'mon Al. You're 32-years-old! Too old to be still going out, chasing women who you don't even know. If you haven't met that special some one by now, then you probably won't. Face it Alan, you're alone, there's nothing wrong with that, is there? (Finishes taking shoes off)

ALAN (To audience) I went to this wedding - it was about a month ago. It was with a bunch of old school friends from University. And they were all married or living with some one - some even had kids. And then there was me. No one ever gave me the chance to explain myself - that I just haven't met that 'special some one' yet. They just all assumed that I would be alone.

(Furious) And maybe I would meet some one if I could ever get out of the house without it costing me an arm and a leg! But none of them ever thought about that, eh?!? None of them ever thought about that whenever I wanna go out - to do anything at all - I have to book one of these special buses! I feel like such a baby - having to phone them up ' $\mathrm{Hi}$, can I please go out tomorrow?'

(Calming down) It's as if we disabled people need permission to be out in public! As if we're not supposed to go out - to parties - and have fun and actually meet people!

And then I get to one of those parties like the one on the week-end. I get myself there and then no one talks to me. It was up to me to push my walker between people and try to blend into whatever they may be talking about. And when I did, their conversation would stop dead! All anyone ever said to me was, "Do you want another beer?" (Laughs) I was getting 
pretty drunk, and I hadn't even touched any of my own beer yet. Then this person, she hands me a beer and says, "Here you go, sweetie." I should have told her to FUCK OFF!

But instead I took her beer, and then sat as far away as I could from everyone else at that party. (Moves center-stage and sits on the chair) That's when Linda sat down beside me, and I remember thinking 'Oh shit, not another one!'

But the moment we started talking I could tell - right away - we connected. (Pause) It was her eyes - the way she looked at me. When she was looking at me, it felt like she was really looking at me. You should have seen her at the party. She was so beautiful.

(Jumps off the chair. Frustrated) And now I have a date with her and I can't even get there! (Pause, calmer) Well, I could get there if I was willing to call a cab and end up spending 80 -bucks tonight.

(Pause) But I cannot go around spending all that money every time I just happen to like some woman's eyes! (Starts taking his shirt off) I'm going to just get undressed, go to bed, and forget all about Linda. Forget all about our date tonight.

ALAN (Finishes taking shirt off) It would have been nice if Linda did turn out to be some one special. I remember my last girlfriend - Carol. She could always make me laugh. Even when it felt like my whole world was falling apart, she could make me laugh it off. Just create a new world, she'd say, and we almost did create our own little world. We would spend hours just laying with each other. Her hands forever touching my naked body. And she'd whisper into my ear, "Alan, you're perfect - and you're all mine!"

(Laughs) That gave me such a surge of energy.(runs across down-stage, on knees - arms out-stretched showing off his bare chest) I felt like running out into the world naked and saying "Hey everyone! Look! Look at me! I'm perfect!"'

(Puts arms down) I wonder how long Linda will wait for me. (Chuckles) As if she's even there. She probably didn't believe we were really going to be dancing tonight. When I told her to meet me at the Mercury Lounge, she said "How are you gonna get in? There's two flights of stairs going up!”

I told her I get in like everyone else (starts crawling) - up those stairs one by one - except I'm doing it on my hands and knees. There's so many stairs in Ottawa that, if some one wants to go out, listen to some music, 
drink some beer, they pretty well have to go up or down stairs. I told Linda that, as a result, I spend a lot of time on my hands and knees especially if it involves dancing with a beautiful woman.

Linda laughed at that one, and then said "I like men who come crawling up to me on their hands and knees."

(Laughs. Pause, thinks) I should go. I mean, she might be there right now, and I'm here, still waiting for that special bus (chuckle) Still deciding whether or not to go. How stupid can I get?

(Starts to put shirt back on. stops. Looks at watch) Shit, look at the time! I'm already an hour late! (Throws shirt across the stage) By the time I call a cab, it gets here, I get in the cab, I get over there and get up all those stairs, there's no way Linda will still be there, no matter how much she might have wanted me tonight.

(Angry) Another date ruined! I hate you, Para Transpo! ·

Alan's phone then rings. Alan freezes, not knowing what to do. We hear his answering message playing, "You have reached Alan. I am probably either on the bus, waiting to get on the bus, or just getting off of the bus. Please leave a message." Then we hear a voice leaving a message from a crowded bar. "Hi Alan. It's me, Linda. (Playful) Well, I'm getting pretty anxious to see you come crawling up those stairs on your knees - just for me. (Giggles) I haven't waited this long for a man before. Usually I make them wait. (slightly impatient) Where are you? You better still be coming. I don't know how much longer I'11 wait. Bye."

While message has been playing, Alan is first bewildered, then stunned that Linda would still be at the bar. He suddenly realizes that he better put his shirt and shoes back on and get himself to the bar. He is excitedly running around, not knowing what to do first. Then he realizes Linda is still on the phone, and that she's saying bye.

ALAN No, wait! (Lunging, picks up the phone) Linda! Are you still there? (Laughs) Ya! I'm still coming!

(Starts running off stage-left carrying his shoes. Stops. Remembers audience is still watching. Yells out to audience) Woo-hoo! 80-bucks, here I come!

(runs off-stage yelling TAXI! TAXI!

\section{BLACK-OUT}

